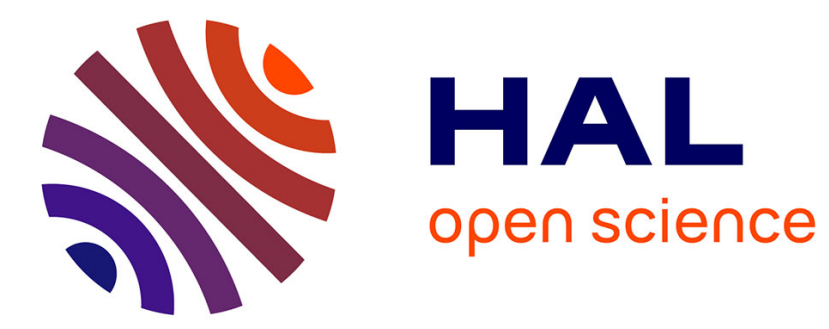

\title{
Magnetization of the La Palma Seamount Series: Implications for Seamount Paleopoles
}

Jeff Gee, Hubert Staudigel, Lisa Tauxe, Thomas Pick

\section{To cite this version:}

Jeff Gee, Hubert Staudigel, Lisa Tauxe, Thomas Pick. Magnetization of the La Palma Seamount Series: Implications for Seamount Paleopoles. Journal of Geophysical Research, 1993, 98767, pp.11743-11754. 10.1029/93JB00932 . insu-01864349

\section{HAL Id: insu-01864349 \\ https://hal-insu.archives-ouvertes.fr/insu-01864349}

Submitted on 29 Aug 2018

HAL is a multi-disciplinary open access archive for the deposit and dissemination of scientific research documents, whether they are published or not. The documents may come from teaching and research institutions in France or abroad, or from public or private research centers.
L'archive ouverte pluridisciplinaire HAL, est destinée au dépôt et à la diffusion de documents scientifiques de niveau recherche, publiés ou non, émanant des établissements d'enseignement et de recherche français ou étrangers, des laboratoires publics ou privés. 


\title{
Magnetization of the La Palma Seamount Series: Implications for Seamount Paleopoles
}

\author{
JefF Geg, ${ }^{1}$ Hubert Staudige, ${ }^{2}$ Lisa TaUXB, ${ }^{3}$ and Thomas Pick \\ Scripps Institution of Oceanography, La Jolla, Callfornia \\ YVES GALLET
}

Institut de Physique du Globe de Paris

\begin{abstract}
Paleopoles determined from seamount magnetic anomalies constitute the major data source for the Pacific apparent polar wander path, but relatively little is known about the processes of remanence acquisition in seamounts. Since magnetic anomalies reflect both natural remanence (NRM) and the induced field, it is important first to assess whether the NRM is likely to represent an original field direction and second to constrain the magnitude of the induced component. To this end, we present paleomagnetic data from an uplifted, subaerially exposed section through a seamount on La Palma, Canary Islands. The Pliocene Seamount Series of La Palma comprises a $>6 \mathrm{~km}$ sequence of alkalic extrusives and intrusives which includes all lithologies likely to be volumetrically important in seamounts. The structural tilt of the Seamount Series allows separation of early thermal or chemical remanence from magnetization components acquired after tilting (e.g., viscous remanence). The NRM provides a poor indication of the original magnetization direction, although the characteristic magnetization of many La Palma samples is compatible with the original pretilt direction. Hydrothermal alteration has resulted in the production of Ti-poor magnetite and an increasing contribution of hematite with increasing degree of alteration. More importantly, well-defined magnetization directions which deviate from any reasonable geomagnetic direction at La Palma can be attributed to hydrothermal alteration in a different polarity than prevalent during the original magnetization. Based on a comparison of the magnitude of low-stability components of magnetization and laboratory acquisition of viscous remanence and previous estimates of the induced magnetization, we conclude that viscous and induced magnetization probably account for $15-25 \%$ of the total magnetization of seamounts. The resulting paleopole bias is a function of the polarity and paleolatitude of the seamount and ranges from $4^{\circ}$ to $16^{\circ}$ for Cretaceous seamounts in the Pacific.
\end{abstract}

\section{INTRODUCTION}

Magnetic anomalies associated with seamounts have long been recognized as a source of tectonic information, and seamount paleopoles have been particularly useful in reconstructing the history of the Pacific plate [e.g., Francheteau et al., 1970] where traditional, land-based paleomagnetic sampling is rarely possible. Although paleomagnetic data from drillcores, sediment distribution patterns, and skewness of lineated crustal anomalies provide complementary tectonic information [Gordon and Cox, 1980], seamount poles remain the principal source for the Pacific apparent polar wander path and, indeed, are sometimes held as the standard by which these additional data are judged [e.g., Gordon, 1990].

The nonuniqueness inherent in the determination of seamount paleopoles requires that some assumptions be made concerning the magnetization sources (see Parker et al. [1987] for a review). Early models utilized the assumption of uniform magnetization to determine the best fit magnetization in a least squares sense [Vaquier, 1962]. Although com-

\footnotetext{
${ }^{1}$ Now at Lamont-Doherty Earth Observatory, Palisades, New York ${ }^{2}$ Now at Vrije Universiteit Amsterdam, Faculteit der Aardwetenschappen.

${ }^{3}$ Also at Fort Hoofddijk Paleomagnetic Lab, Utrecht.
}

Copyright 1993 by the American Geophysical Union.

Paper number 93JB00932.

0148-0227/93/93JB-00932\$05.00. plex anomaly patterns may be accommodated by arbitrarily subdividing the seamount into regions of uniform magnetization [e.g., McNutt, 1986], the spatial coherence of residuals suggests the standard least squares inversion is based on an improper statistical model [Parker, 1988]. The seminorm minimization technique of Parker et al. [1987] incorporates both uniform and nonuniform components, providing the most uniform model compatible with the observed anomaly and thereby estimating the minimum degree of nonuniformity in the magnetization of the seamount demanded by the data. The lognormal distribution of magnetization intensities observed in seamount rocks [e.g., Kono, 1980; Gee et al., 1989] suggests that nonuniformity in intensity is probably the rule rather than the exception. In recognition of this large intensity variation, Parker [1991] developed an ideal body modeling technique for seamount magnetization which constrains the solution to have uniform direction while allowing intensity to vary. Directional information can still be recovered despite relaxation of the intensity constraints, but the location of seamount paleopoles is much more poorly constrained than commonly assumed.

Although these recent models have made significant progress in addressing the nonuniformity of seamount magnetic sources, bias introduced by viscous and induced contributions is difficult to incorporate in the models. Comparison of modeling results from normal and reversely magnetized seamounts [Hildebrand and Staudigel, 1986; Bryan and Gordon, 1991] suggests a combined contribution of up to $25 \%$ for induced and viscous components. A similar bias from induced magnetization ( $15 \%$ of total magnetization) has 
been suggested for large seamounts with a significant portion of intrusive material based on results from the La Palma Seamount Series [Gee et al., 1989]. In addition, the presence of multiple polarities is often difficult to assess from models. For example, the ideal body solution for Jasper Seamount does not require mixed polarity [Parker, 1991] despite the demonstrably long duration (>7 my.) of volcanism which strongly supports the presence of both normal and reversed polarity rocks [Pringle et al., 1991]. Finally, the effects of progressive hydrothermal alteration (perhaps in different polarity intervals) on the original magnetization are poorly understood.

In this paper we discuss the origin of the magnetization in an uplifted, tilted section through a seamount exposed on La Palma, Canary Islands. The La Palma Seamount Series provides a unique opportunity to study the magnetic properties and origin of the magnetization in seamounts. In contrast to dredging and drilling, which sample only the outermost part of the volcanic edifice, the exposures of the Seamount Series provide about $4 \mathrm{~km}$ of stratigraphic relief and include a wide range of extrusives and intrusives which encompass all lithologies likely to be important in seamounts. Age constraints for the Seamount Series and the overlying subaerial flows allow general correlation to the geomagnetic reversal time scale and facilitate evaluation of the role of multiple polarities in generating inhomogeneous magnetization. The tilting of the seamount sequence $\left(\sim 50^{\circ}\right)$ allows separation of pretilt thermal or chemical components from later viscous, chemical and thermal magnetizations acquired after tilting. While the magnitude of tilting in La Palma is probably atypical, the effect is analogous to the latitudinal translation common in Pacific seamounts. Results from La Palma indicate that most assumptions made in modeling seamount anomalies may be questionable, but our data also provide an estimate of the bias inherent in seamount paleopoles which may ultimately contribute to a more accurate Pacific apparent polar wander path.

\section{Geology of the la Palma Seamount Series}

La Palma is the northwesternmost island of the Canary island chain and is located on Jurassic oceanic crust [Hayes and Rabinowitz, 1975]. Schmincke [1976] has summarized the geology of the Canary Islands and a recent review of the geology of La Palma is given by Staudigel and Schmincke [1984]. The oldest rocks exposed on La Palma are biostratigraphically dated at 3-4 Ma [Staudigel, 1981] and volcanism extends to historic times [e.g., Middlemost, 1972]. The island consists of two major structural units. The Pleistocene subaerial lavas of the Coberta Series cover more than $90 \%$ of the island and unconformably overlie the Pliocene submarine and plutonic basement complex [Afonso, 1974]. The oldest lavas of the Coberta Series are dated at 1.61 Ma [Abdel-Monem et al. 1972] (recalculated using the decay constants of Steiger and Jäger [1977]). The basement complex is a $>6 \mathrm{~km}$ section of alkalic extrusives and intrusives exposed within the Caldera de Taburiente and the steep-walled canyon (Barranco de las Angustias) which drains the caldera (Figure la inset). Erosion rates in the canyon are high (1-2 mm/yr as determined by erosion of 1973 drillholes), providing extremely fresh exposures along the canyon bottom.

The basement complex comprises three units: an approximately $2500 \mathrm{~m}$ ( $1800 \mathrm{~m}$ prior to inflation by intrusives) layered sequence of entirely submarine extrusives and volcaniclastics, three generations of alkalic dikes/sills, and a basal plutonic sequence (Figure 1b). The submarine extrusive series is consistently bedded with a dip of $48^{\circ}$ along an azimuth of $230^{\circ}$ [Staudigel, 1981], which represents a tilt roughly radial with respect to the present center of intrusive activity in the southeastern and central portions of the caldera. The extrusive series consists predominantly of pillow lavas (50\%), pillow fragment breccias, submarine scoriaceous breccias and hyaloclastites (terminology of Fisher and Schmincke [1984]) and ranges in composition from alkalic basalt to mugearite and rare trachyte. Three generations of dikes and sills are observed in the basement complex [Staudigel and Schmincke, 1984; Staudigel et al., 1986]. The earliest generation of dikes (Group I) is oriented approximately orthogonal to the bedding of the layered extrusive series. On the basis of their orientation and the similarity in both composition and alteration history to the extrusive series, these dikes are interpreted as feeders for the extrusive series. Sills (Group II) occur within the layered extrusive series, parallel to bedding, and also form a $2 \mathrm{~km}$ sheeted sill swarm which underlies the extrusive sequence. Crosscutting relationships suggest that most of the sills are younger than the Group I dikes [Staudigel et al., 1986]. Group III dikes generally have steep dips, may crosscut the overlying Coberta lavas and are typically less altered than the country rock. These dikes are interpreted as members of a radial dike swarm feeding the Coberta lavas. Isotopic age dating suggests an age range of 0.51 to $0.80 \mathrm{Ma}$ for the radial dikes in the Barranco de las Angustias [Staudigel et al., 1986]. The basal plutonic complex is exposed in the Caldera de Taburiente primarily as numerous, small (10s to $100 \mathrm{~s}$ of $\mathrm{m}$ ) gabbro, leucogabbro and ultramafic intrusions, some of which are probably associated with the subaerial Coberta lavas. Small leucocratic gabbro intrusions also occur within the extrusive portion of the sequence. Staudigel and Schmincke [1984] refer to the extrusives, feeder dikes and sills as the Seamount Series. For simplicity, and because such rocks are expected to occur in seamounts as well, we will also use the term to include the alkalic gabbros of the basal plutonic complex.

The Seamount Series has been subjected to hydrothermal alteration [Hernandez-Pachecho and Fernandez-Santin, 1975; Staudigel, 1981]. The upper part of the sequence is characterized by low-temperature assemblages of smectite, analcime, carbonate and low-temperature zeolites. Alteration increases, both in pervasiveness and extent, with stratigraphic depth. Interlayered chlorite/smectites give way to epidote and (locally) actinolite (Figure 1). The upper stability limit of analcime corresponds to a temperature of approximately $200^{\circ} \mathrm{C}$ [Liou, 1971]. The first appearance of epidote in hydrothermal systems occurs at temperatures greater than $200^{\circ}$ to $250^{\circ} \mathrm{C}$ and actinolite denotes temperatures in excess of $\sim 300^{\circ} \mathrm{C}$ [Bird et al., 1984]. The silicate assemblages therefore suggest a fossil geothermal gradient of approximately $200^{\circ} \mathrm{C} / \mathrm{km}$. The alteration assemblages are similar to those found in upwelling regions of present day hydrothermal systems in basaltic lavas (e.g., Iceland [Palmasson et al., 1979] and Reunion Island [Demange et $a l ., 1989])$. The absence of similar alteration in the Coberta lavas and in recent pyroclastic deposits on the flanks of the canyon indicates that the metamorphism of the extrusives, Group I dikes, and the sill complex was associated with seamount construction. Later localized hydrothermal activity, 


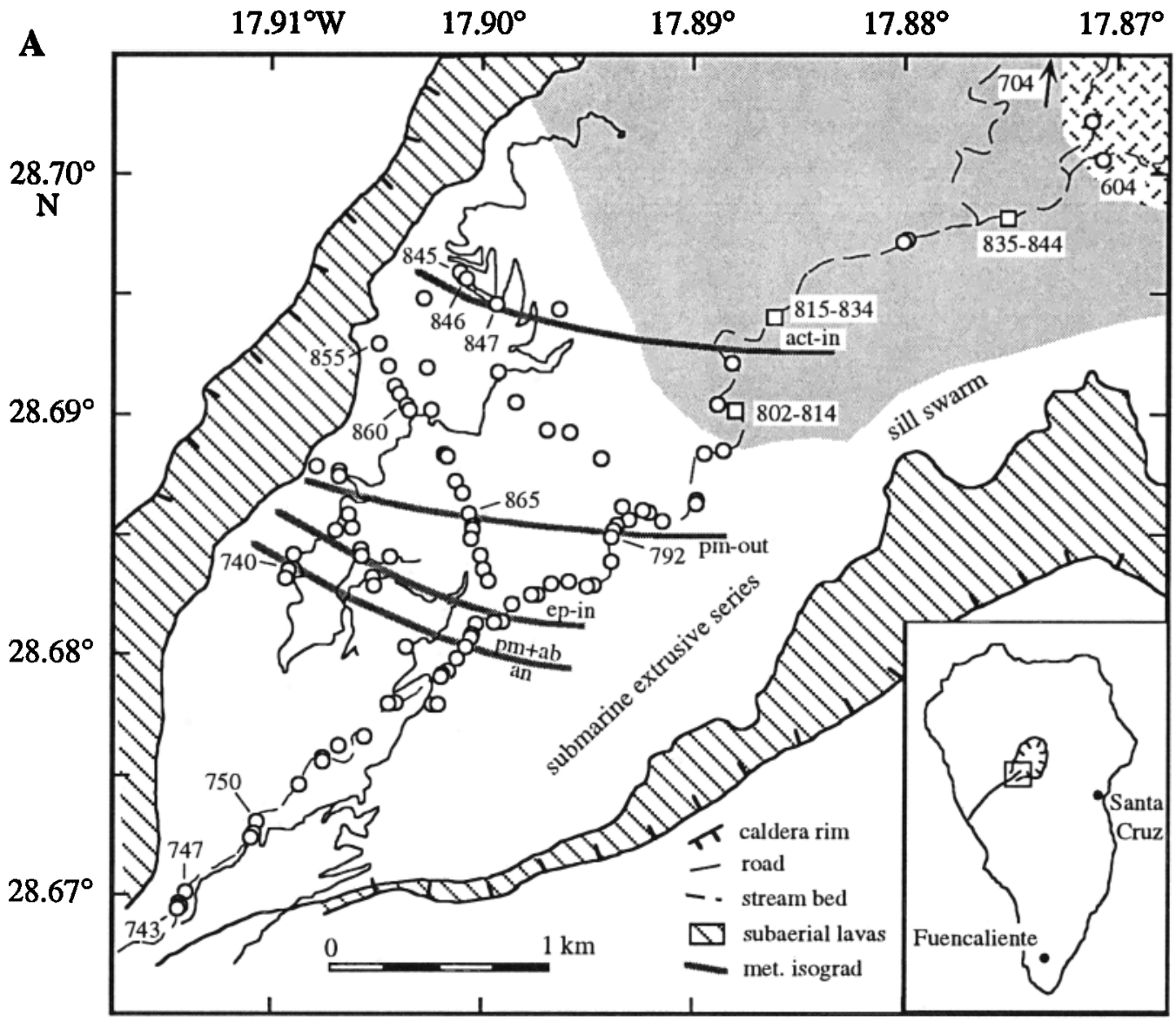

B

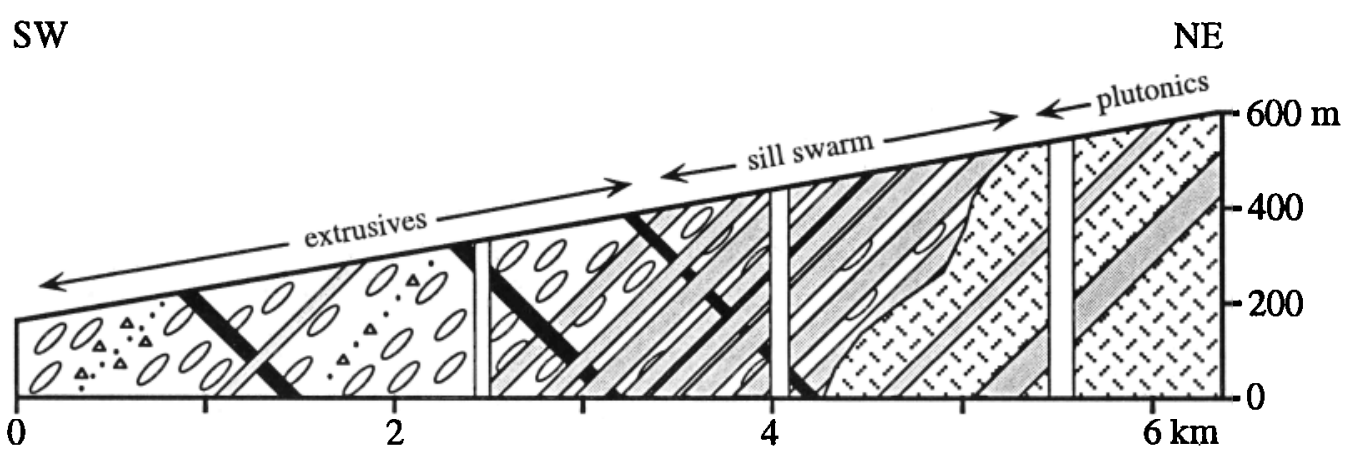

Fig. 1. Paleomagnetic sample locations and schematic cross section of La Palma Seamount Series. (a) Sample locations and simplified geology shown for westernmost Caldera de Taburiente and Barranco de las Angustias (see inset). Squares indicate detailed sill sampling sites and only sites discussed in the text are labeled. An additional 18 sites are widely dispersed within the caldera to the northeast of the mapped region. Plutonics, sill swarm and extrusives are indicated by hatched pattern, grey and white, respectively. Note that southeastern margin of canyon has not been mapped. Metamorphic isograds modified from Staudigel [1981] based on present sample collection. Labels: an, analcime; pm, pumpellyite; ab, albite; ep, epidote; act, actinolite. (b) Simplified cross section approximately parallel to the canyon bottom. Extrusives are consistently bedded and dip $\sim 50^{\circ}$ to SW. Crosscutting relationships of Group I feeder dikes (solid), Group II sills (grey), and Group III vertical dikes (white) and plutonics shown schematically.

as evidenced by sulfur-rich hydrothermal waters, is currently present in the southeastern and central portions of the caldera.

The tilt of the extrusive series plays a central role in determining the origin of the magnetization in the Seamount Series. Although bedding is less obvious in volcanic sequences than in sediments, layering in finegrained hyaloclastites, flattened pillow bottoms overlying bedded hyaloclastites, and the upper surfaces of partiallydrained pillows yield a consistent attitude of $48^{\circ}$ dip toward $230^{\circ}$ (Table 1). Constructional slopes of seamounts may be locally quite steep. For example, steep-sided $\left(50-60^{\circ}\right)$ pillow walls (10-20 m high) have been described from the submerged portion of Kilauea's east rift zone [Fornari et al., 1978] although the slopes of seamounts are typically $<20^{\circ}$ [e.g., Lonsdale and Batiza, 1980; Barone and Ryan, 1990]. The orientation of geopetal structures (e.g., the single drained pillow surface in Table 1) and the consistent bedding of fine-grained (sand-sized) hyaloclastites in the Seamount Series suggests that the present bedding approximates the paleohorizontal. 
TABLE 1. Bedding Measurements for the Seamount Series

\begin{tabular}{|c|c|c|c|}
\hline $\begin{array}{l}\text { Attitude } \\
\text { Dip/Dip } \\
\text { Direction }\end{array}$ & $\begin{array}{l}\text { Estimated } \\
\text { Error \& }\end{array}$ & $\begin{array}{l}\text { Measurement } \\
\text { Type }\end{array}$ & $\begin{array}{l}\text { Measurement } \\
\text { Location \# }\end{array}$ \\
\hline $44 / 228$ & + & layered hyaloclastite & unit 2 \\
\hline $55 / 235$ & +++ & pillow bottom & base of unit 5 \\
\hline $55 / 232$ & +++ & pillow bottom & base of unit 5 \\
\hline $58 / 245$ & ++ & pillow bottom & base of unit 5 \\
\hline $54 / 235$ & ++ & layered hyaloclastite & top of unit 10 \\
\hline $40 / 240$ & ++ & $\begin{array}{l}\text { hyaloclastite in } \\
\text { pillow interstices }\end{array}$ & unit 10 \\
\hline $41 / 232$ & t++ & pillow bottom & base of unit 11 \\
\hline $45 / 228$ & +++ & pillow bottom & base of unit 11 \\
\hline $45 / 225$ & +++ & pillow bottom & base of unit 11 \\
\hline $45 / 238$ & +++ & pillow bottom & base of unit 11 \\
\hline $25 / 225^{*}$ & + & $\begin{array}{l}\text { layering in pillow } \\
\text { stringer breccia }\end{array}$ & unit 12 \\
\hline $35 / 190 *$ & + & $\begin{array}{l}\text { layering in pillow } \\
\text { stringer breccia }\end{array}$ & unit 12 \\
\hline $50 / 220$ & +++ & pillow bottom & base of unit 12 \\
\hline $50 / 240$ & +++ & pillow bottom & base of unit 12 \\
\hline $58 / 251 *$ & ++ & pillow bottom & base of unit 12 \\
\hline $53 / 259 *$ & t+ & pillow bottom & base of unit 12 \\
\hline $53 / 195 *$ & ++ & hyaloclastite & top of unit 13 \\
\hline $50 / 225$ & ++ & $\begin{array}{l}\text { layering in pillow } \\
\text { fragment breccia }\end{array}$ & base of unit 13 \\
\hline $43 / 206 *$ & ++ & pillow bottom & base of unit 14 \\
\hline $58 / 219 *$ & ++ & pillow bottom & base of unit 14 \\
\hline $52 / 224$ & ++ & layered hyaloclastite & top of unit 15 \\
\hline $48 / 220$ & t++ & pillow bottom & base of unit 15 \\
\hline $48 / 222$ & +++ & pillow bottom & base of unit 15 \\
\hline $40 / 225$ & +t+ & $\begin{array}{l}\text { partially drained } \\
\text { pillow }\end{array}$ & unit 17 \\
\hline $48 / 246$ & ++ & pillow bottom & base of 'unit 19 \\
\hline $48 / 245$ & +++ & layered hyaloclastite & unit 20 \\
\hline $50 / 244$ & t+t & layered hyaloclastite & unit 20 \\
\hline $45 / 215$ & + & - & water channel \\
\hline $48 / 220$ & + & - & water channel \\
\hline $45 / 222$ & + & $\begin{array}{c}\text { hyaloclastite in } \\
\text { ankaramitic pillows }\end{array}$ & - \\
\hline $48 / 230$ & & weighted mean & \\
\hline
\end{tabular}

* Measurements from this study, remaining data from Staudigel [1981].

\# With the exception of the last three data, all measurements are from the base of the Barranco de las Angustias. Unit numbers from Staudigel and Schmincke [1984].

\& Qualitative error estimate: $+++\left(5^{\circ}\right),++\left(5-10^{\circ}\right),+\left(>10^{\circ}\right)$.

We have used the observed layering of the extrusive series as the basis for our structural correction. Paleomagnetic data from the least altered pillow lavas in the Seamount Series provide independent support for this structural correction. The mean characteristic magnetization direction obtained from these ten sites $\left(1.6^{\circ}, 50.3^{\circ}\right.$; tilt corrected) is statistically indistinguishable from the expected geocentric axial dipole (GAD) direction at La Palma $\left(0^{\circ}, 48^{\circ}\right)$. While original paleoslopes cannot be excluded, reasonable slopes (up to $10^{\circ}$ ) would have only a minor effect on our structural correction, altering the azimuth of the rotational axis by a maximum of $15^{\circ}$ with little change in the dip. The GAD direction at La Palma and the tilt of the Seamount Series therefore yield four expected magnetization directions (in present day coordinates) for comparison with the observed paleomagnetic data. All magnetic data in this paper are in present day coordinates unless otherwise noted. We refer to the normal $\left(0^{\circ}, 48^{\circ}\right)$ and reversed polarity $\left(180^{\circ},-48^{\circ}\right)$ GAD directions as the expected posttilt directions and the corresponding GAD directions corrected for the tilt of the Seamount Series as the expected pretilt normal $\left(19^{\circ}, 10^{\circ}\right)$ and reversed $\left(199^{\circ},-10^{\circ}\right)$ directions. We estimate the uncertainty of the pretilt directions to be $\sim 10^{\circ}$ owing to the possible errors in the structural correction. This error is similar to the dispersion in paleomagnetic directions $\left(\sim 12^{\circ}\right)$ expected at La Palma based on the latitudinal dependence of virtual geomagnetic pole dispersion from paleosecular variation [Cox, 1970; McFadden and McElhinny, 1984].

\section{SAMPLE COLLECTION}

Over 1200 oriented cores ( $\sim 200$ paleomagnetic sites) were collected from the La Palma Seamount Series during two sampling trips in 1985 and 1988 (Table 2). Standard paleomagnetic cores were drilled and oriented with a magnetic compass. Some cores were also oriented with a sun compass. Comparison of the two methods indicated no bias in the magnetic compass orientations, and the sun compass readings indicate a magnetic declination nearly identical to the IGRF declination at the site $\left(-10^{\circ}\right)$. More than $90 \%$ of the sites were located in the layered extrusive series and sill/dike swarm (Figure 1a). Approximately 90 sites were drilled in dikes/sills, including three localities with 10-15 dikes/sills each. Half of these were identified as Group II sills, primarily on the basis of their attitude (mean dip/direction of $\operatorname{dip} 54^{\circ} / 223^{\circ}$ ), with equal numbers of samples from Group I and Group III dikes. More than 60 pillow sites span the range of compositions and alteration temperatures found in the Seamount Series. The volcaniclastic units sampled (25 sites) were primarily pillow fragment breccias, lapillistones and scoriaceous pillow breccias. Gabbros within the extrusive series and gabbro screens within the sill complex were sampled where possible. The remaining $10 \%$ of the sites sampled gabbros and dikes at 18 widely spaced sites within the caldera (not shown in Figure 1a).

\section{USE OF THE SUM OF VECTOR DIFFERENCE MAGNITUDES}

The Seamount Series samples exhibit both normal and reversed polarity characteristic magnetizations and most samples have a low-stability component of normal polarity, which often significantly reduces the initial remanent intensity of reversed polarity samples (Figure 2a). As a result, parameters such as blocking temperature and median destructive field, which are based on the natural remanent magnetization (NRM), are biassed by polarity. To ameliorate this problem we have used the vector difference sum (VDS) as a basis for calculating magnetic parameters such as blocking termperature. The sum of the vector difference magnitudes between successive demagnetization steps gives an estimate of the sample's original NRM, assuming that the secondary component is acquired by reorientation of moments in existing grains rather than net addition of magnetic material. This is in effect the sum of each component aligned to a common direction. The VDS is, of course, also artificially increased by any noise in the directional measurement and artificially reduced if an insufficient number of demagnetization steps were made to 
TABLE 2. Summary of Magnetic Properties of La Palma Lithologies

\begin{tabular}{|c|c|c|c|c|c|c|c|c|}
\hline Lithology & $\begin{array}{c}\text { Number } \\
\text { of } \\
\text { Specimens }\end{array}$ & $\begin{array}{c}\text { Number } \\
\text { of } \\
\text { Sites }\end{array}$ & $\begin{array}{c}\mathrm{NRM} \\
\mathrm{A} / \mathrm{m}\end{array}$ & $\begin{array}{l}\text { Koenigsberger } \\
\text { Ratio, Q \& }\end{array}$ & $\begin{array}{l}\text { Low-stability } \\
\text { Component, } \\
\text { \% VDS }\end{array}$ & $\underset{\mathrm{mT}}{\mathrm{MDF}}$ & ${ }^{\mathrm{T}} \mathrm{Cb}$ & $\begin{array}{l}\text { Characteristic } \\
\text { Remanence } \\
\text { Directions }\end{array}$ \\
\hline Gabbros & 229 & 16 & 7.28 & 3.05 & 14.9 & 18.1 & 605 & \\
\hline $\begin{array}{l}\text { In extrusives/sills } \\
\text { In caldera }\end{array}$ & $\begin{array}{c}65 \\
164\end{array}$ & $\begin{array}{c}5 \\
11\end{array}$ & $\begin{array}{l}8.55 \\
6.78\end{array}$ & $\begin{array}{l}2.66 \\
3.21\end{array}$ & $\begin{array}{l}22.4 \\
12.1\end{array}$ & $\begin{array}{l}21.6 \\
17.2\end{array}$ & $\begin{array}{l}610 \\
605\end{array}$ & $\begin{array}{l}\text { pretilt } \\
\text { posttilt }\end{array}$ \\
\hline Dikes/Sills & 799 & 88 & 2.46 & 1.88 & 35.5 & 20.6 & 595 & \\
\hline $\begin{array}{l}\text { Group I (feeder) } \\
\text { Group II (sills) } \\
\text { Group III (vertical) }\end{array}$ & $\begin{array}{l}176 \\
372 \\
251\end{array}$ & $\begin{array}{l}22 \\
44 \\
22\end{array}$ & $\begin{array}{l}2.14 \\
2.47 \\
2.67\end{array}$ & $\begin{array}{l}1.79 \\
1.72 \\
2.19\end{array}$ & $\begin{array}{l}40.3 \\
29.6 \\
44.6\end{array}$ & $\begin{array}{l}14.1 \\
26.0 \\
16.4\end{array}$ & $\begin{array}{l}585 \\
605 \\
575\end{array}$ & $\begin{array}{l}\text { pretilt } \\
\text { pretilt to posttilt } \\
\text { posttilt }\end{array}$ \\
\hline Pillow lavas \# & 731 & 66 & 3.87 & 5.29 & 21.7 & 34.0 & 615 & \\
\hline $\begin{array}{l}\text { No epidote } \\
\text { Ep-pm } \\
\text { Pm-act } \\
\text { >Actinolite }\end{array}$ & $\begin{array}{c}130 \\
227 \\
330 \\
44\end{array}$ & $\begin{array}{c}13 \\
18 \\
29 \\
6\end{array}$ & $\begin{array}{l}8.43 \\
4.87 \\
1.89 \\
0.22\end{array}$ & $\begin{array}{c}11.58 \\
5.62 \\
3.00 \\
2.22\end{array}$ & $\begin{array}{l}25.4 \\
16.9 \\
19.7 \\
40.3\end{array}$ & $\begin{array}{l}19.1 \\
39.6 \\
34.0 \\
54.9\end{array}$ & $\begin{array}{l}595 \\
625 \\
620 \\
635\end{array}$ & $\begin{array}{l}\text { pretilt } \\
\text { pretilt } \\
\text { pretilt } \\
\text { pretilt }\end{array}$ \\
\hline Volcaniclastics & 376 & 25 & 3.11 & 5.45 & 15.0 & 26.1 & 605 & \\
\hline $\begin{array}{l}\text { Pillow fragments } \\
\text { Hyaloclastite @ }\end{array}$ & $\begin{array}{l}240 \\
136\end{array}$ & $\begin{array}{l}25 \\
36\end{array}$ & $\begin{array}{l}4.38 \\
0.86\end{array}$ & $\begin{array}{l}6.19 \\
4.15\end{array}$ & $\begin{array}{l}13.5 \\
17.1\end{array}$ & $\begin{array}{l}23.5 \\
30.5\end{array}$ & $\begin{array}{l}605 \\
600\end{array}$ & $\begin{array}{l}\text { random } \\
\text { pretilt }\end{array}$ \\
\hline Subaerial lavas & 86 & & 12.12 & 18.69 & - & - & - & \\
\hline
\end{tabular}

Collection of fully oriented samples forms subset of data reported by Gee et al. [1989]. Arithmetic means are used throughout. NRM is natural remanent magnetization. Low-stability component, median destructive field (MDF), and maximum blocking temperature (Tb) all based on vector difference sum (VDS) as discussed in text.

$\& Q$ is the ratio of the remanent to induced magnetization.

\# Subdivisions based on metamorphic isograds (ep, epidote in; pm, pumpellyite out; act, actinolite in) in Figure 1. Actinolite group includes results from keratophyres.

@ Includes interstitial hyaloclastite material in pillow units and pillow fragment breccias as well as bedded lapillistones.
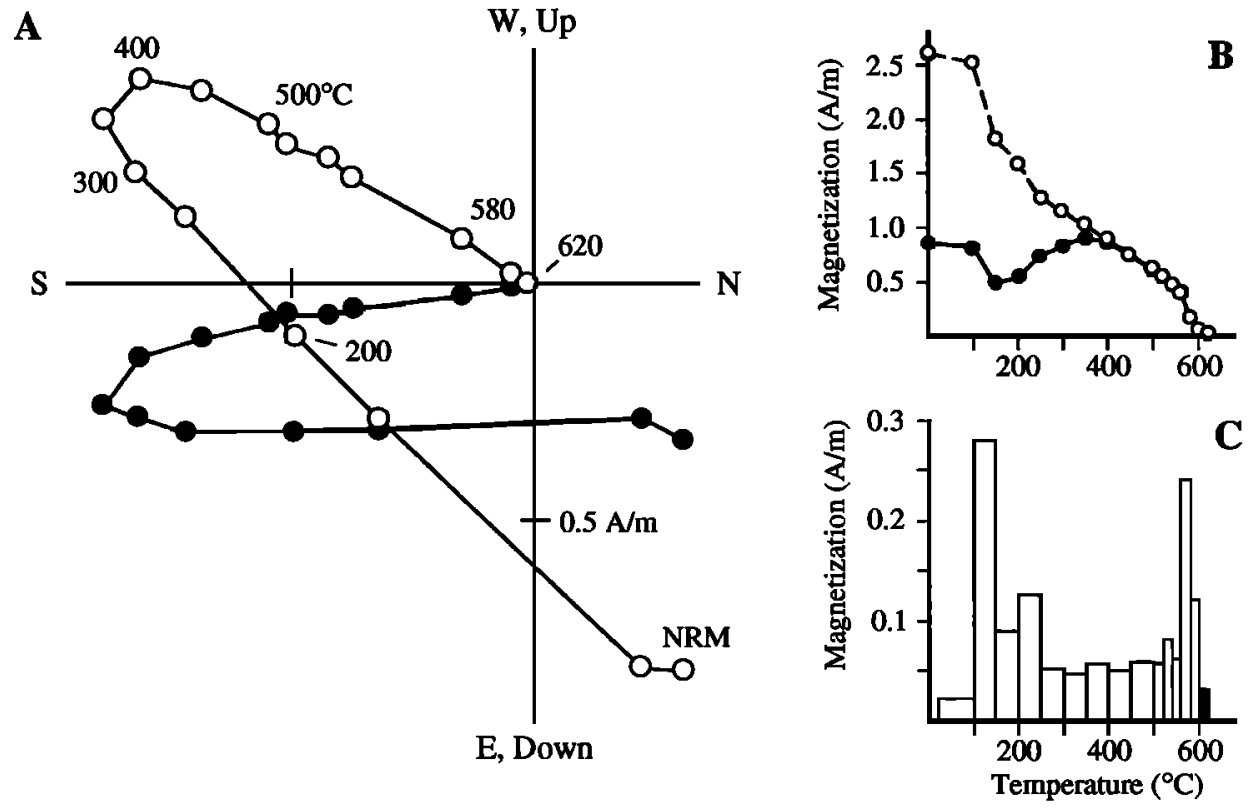

Fig. 2. Illustration of the use of the vector difference sum (VDS). (a) Vector endpoint diagram of thermal demagnetization of a dike sample from La Palma. The dike has a reversed polarity characteristic magnetization $\left(500^{\circ}-620^{\circ} \mathrm{C}\right)$ and a significant normal polarity overprint $\left(100^{\circ}-300^{\circ} \mathrm{C}\right)$. The low-temperature component is estimated as $65 \%$ of the VDS using the technique described in the text. Solid (open) circles are projections of the vector onto the horizontal (vertical) plane. (b) Thermal decay of the NRM (solid circles) and VDS (open circles). Note the significant difference between the original and reconstructed remanent intensities. (c) Histogram of blocking temperatures derived from the VDS. The component remaining above $600^{\circ} \mathrm{C}$ (solid) is used as an estimate of the importance of hematite when this component exceeds $5 \%$ of the VDS. 
clearly delineate the full complexity of the remanence vectors. The effect of noise is small in most cases and is partially offset by the incomplete separation of the two components so that the VDS probably provides a reasonable estimate of the original NRM.

The vector difference method also allows a quantitative estimate of the magnitude of the various components. In the example in Figure 2, the low-stability component (359.4 $44.6^{\circ}$ ) is well defined between $100^{\circ}$ and $300^{\circ} \mathrm{C}$ and the characteristic magnetization $\left(170.0^{\circ},-30.5^{\circ}\right)$ is isolated between $500^{\circ}$ and $620^{\circ} \mathrm{C}$. Using the principal component directions for these well-defined segments, the vector differences in the interval from $300^{\circ}$ to $500^{\circ} \mathrm{C}$ can be expressed as a linear combination of the two known directions in a least squares sense [Press et al., 1986, p. 59]. A similar procedure for estimating the magnitude of components from demagnetization data was suggested by Zijderveld [1967]. We will show later that the low-stability component postdates tilting of the Seamount Series and can reasonably be attributed to a viscous remanence (VRM) acquired at low to moderate temperature. Since temperature is much more efficient than alternating field treatment for removing VRM [Dunlop, 1973], we have used thermal demagnetization curves exclusively for calculating the percentage of secondary magnetization. For this study each thermally demagnetized specimen was typically subjected to 15-20 steps, sufficient for the purpose of calculating the VDS.

\section{RESULTS}

\section{Natural Remanent Magnetization}

The magnetic anomaly of a seamount measured at the sea surface arises from the combined induced and remanent magnetizations, without benefit of magnetic cleaning. Thus, the NRM intensity and direction are the most pertinent data for comparison with anomaly models. The NRM intensities and induced magnetization of the La Palma Seamount Series have been previously reported [Gee et al., 1989]. Two polarities are evident in the NRM data and these data can be arbitrarily separated along the E-W vertical plane and their distributions contoured on an equal area projection (Figure 3). The northern hemisphere (normal polarity) directions are skewed toward the expected pretilt normal direction, but the density maximum $(11.2 \%)$ is located near the posttilt normal GAD direction (Figure 3a). The reversed directions (Figure 3b) have a maximum which lies between the pretilt and posttilt reversed directions. A secondary maximum occurs slightly to the east of the reversed GAD direction and can largely be attributed to samples from gabbroic intrusions. The expected pretilt directions are based on the bedding attitude observed in the layered portion of the Seamount Series and thus strictly apply only to the layered extrusive series, Group I dikes and the sills. Nonetheless, deviations from these expected directions are a general indication of the severity of secondary magnetization in the sequence. Clearly, the original pretilt directions for the Seamount Series are not well represented by the NRM directions as assumed in modeling of seamount anomalies.

The effect of hydrothermal alteration on the NRM intensity is most clearly demonstrated in pillow lavas, where complexities due to differences in cooling rate and original magnetic mineralogy should be minimal (Figure 4). The fossil hydrothermal system exposed on La Palma (Figure 1) is similar to presently active basalt-hosted hydrothermal systems in Iceland [Palmasson, 1979] and on Reunion Island [Demange et al., 1989] and records a geothermal gradient of $\sim 200^{\circ} \mathrm{C} / \mathrm{km}$. Samples from the least-altered portion of the section have NRM intensities comparable to dredged and drilled extrusives from seamounts [e.g., Kono, 1980; Gee et al., 1988]. Progressive hydrothermal alteration results in approximately two orders of magnitude reduction in the NRM intensity over the temperature range $\left(<200^{\circ}\right.$ to $\left.>300^{\circ} \mathrm{C}\right)$ indicated by the silicate assemblages.
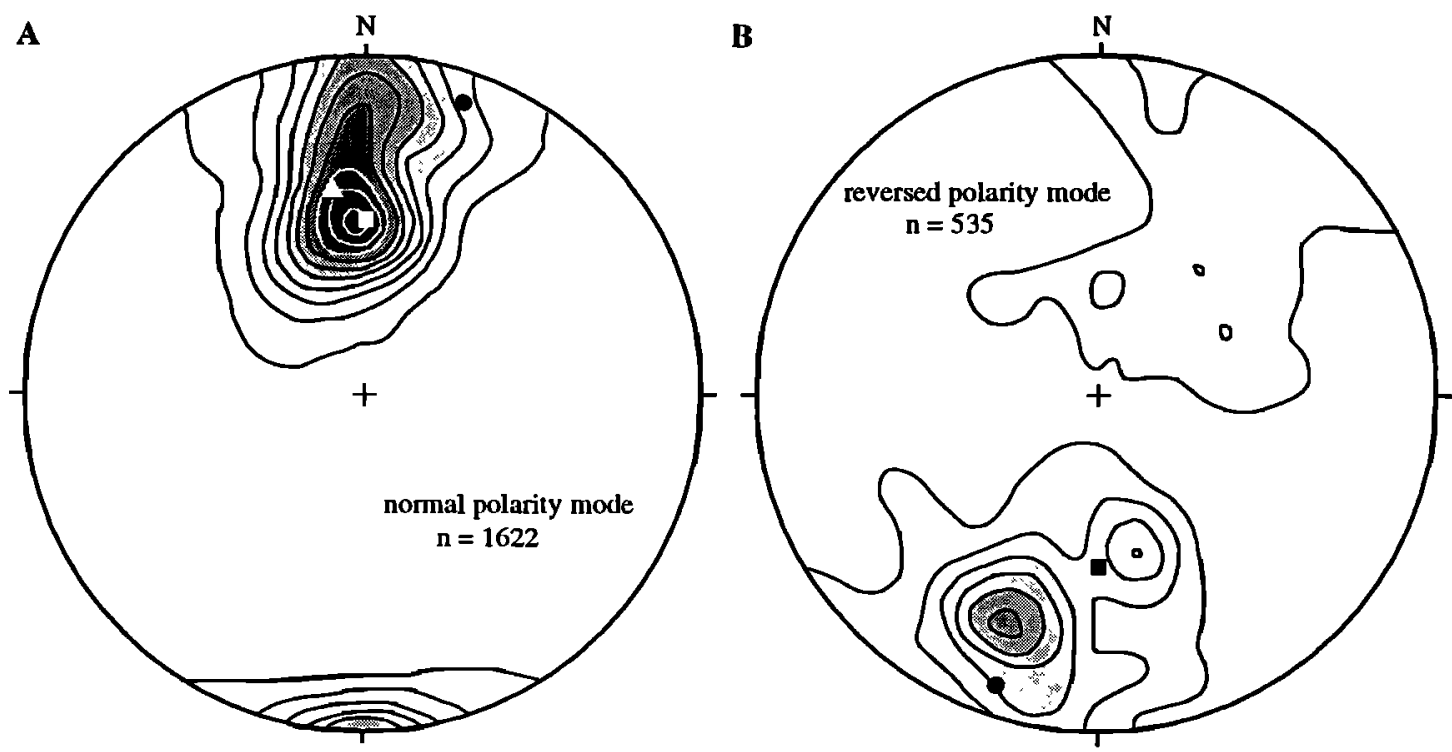

Fig. 3. Equal-area contour plot of NRM directions (in geographic coordinates). (a) Lower hemisphere projection of the northern hemisphere (normal) directions. The maximum density (11.2\%) is located near the posttilt GAD (square) and the present field (triangle) di-rections for La Palma rather than near the expected pretilt direction (circle). (b) Upper hemisphere projection of southern hemisphere (reversed) directions. The maximum density (7.2\%) lies between the GAD reversed direction (square) and the expected, pretilt reversed direction (circle). One percent isodenisty contours are shown. The antipode is plotted for upper hemisphere directions in Figure 3a and lower hemisphere directions in Figure 3b. 

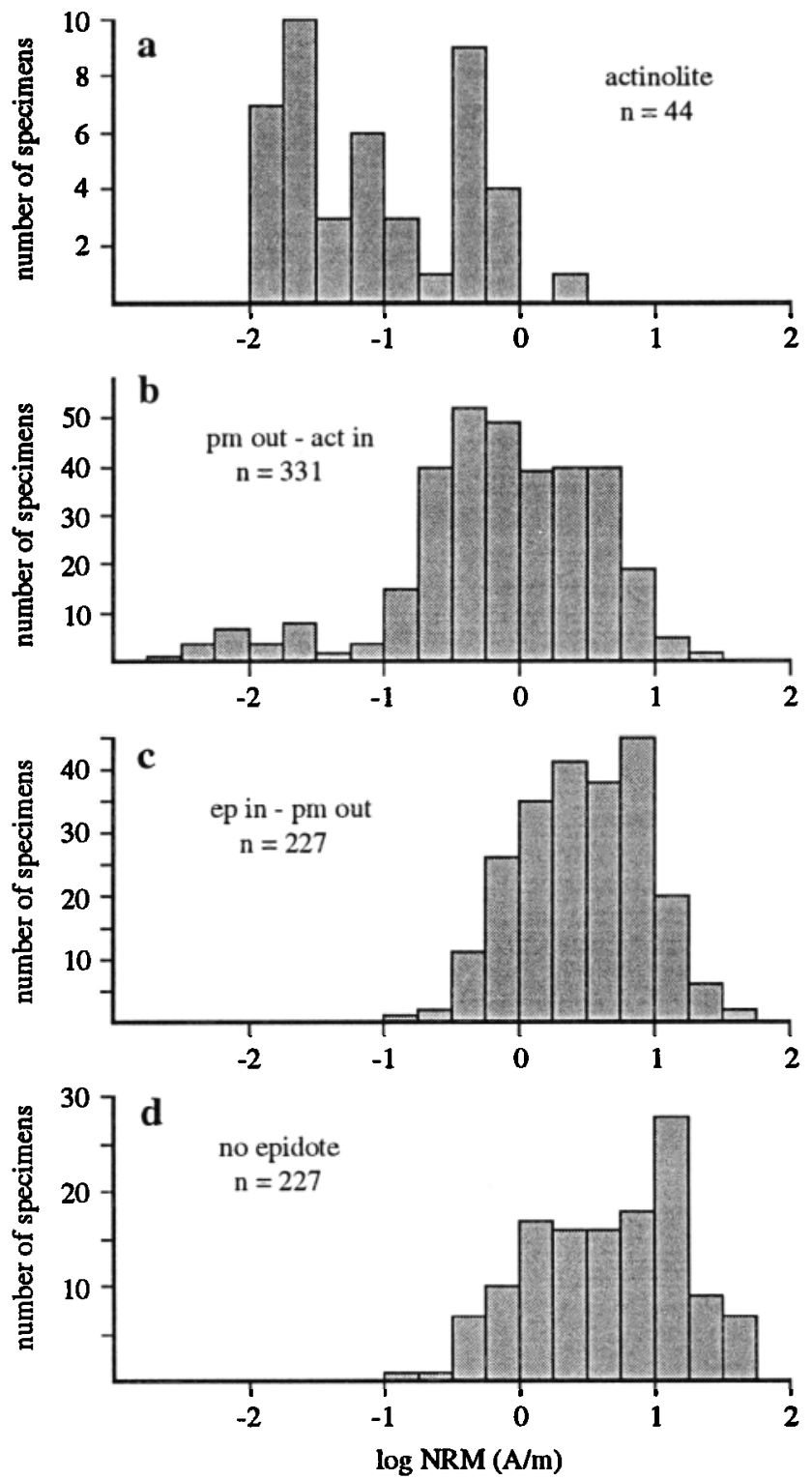

Fig. 4. NRM intensities for pillow lavas as a function of alteration. Note the reduction in intensity by nearly two orders of magnitude over the temperature range $\left(<200^{\circ}->300^{\circ} \mathrm{C}\right)$ indicated by the silicate assemblages. Groupings are based on the isograds shown in Figure 1. Actinolite samples include two keratophyre screens.

\section{Demagnetization Results}

Approximately 1000 specimens were subjected to stepwise thermal or alternating field (AF) demagnetization, with a minimum of three samples from each site. The majority of samples were thermally demagnetized, as this method often provides more reliable results, in $50^{\circ} \mathrm{C}$ steps from $100^{\circ}$ to $500^{\circ} \mathrm{C}$ followed by $20^{\circ} \mathrm{C}$ steps until the directions became random or the sample intensity fell below $1 \%$ of the NRM value. The uniformity of temperature steps was maintained to facilitate comparison of blocking temperature spectra and maximum unblocking temperatures. Components of magnetization were defined by principal component analysis [Kirschvink, 1980] whenever possible. Specimens for which no stable characteristic magnetization could be isolated were analyzed using the great circle method described by McFadden and McElhinny [1988]. A small number of sites $(<10 \%)$ with a circular standard deviation of more than $20^{\circ}$ have been excluded from consideration.

The range of demagnetization behavior in samples from La Palma is illustrated in Figure 5. Approximately 20\% of the samples have univectorial behavior, as defined by a lowstability component $<10 \%$ of the VDS. Univectorial directions compatible with a posttilt magnetization are most common in gabbroic intrusions (Figure 5a) and vertical Group III dikes (Figure 5b) although Group II sills and a few extrusive sites also have single component posttilt magnetizations. Directions compatible with a pretilt magnetization are more typical for the extrusive portion of the Seamount Series as well as many of the Group I and II feeder dikes and sills. Nearly univectorial pretilt directions are particularly common in the pillow lavas of the upper portion of the Seamount Series (Figure 5c). Low-stability components of variable magnitude characterize many sites although the shallow pretilt inclination can be isolated (Figures 5d and 5e). A leucocratic gabbro from within the extrusive series (Figure 5f) illustrates a more complex demagnetization behavior but a pretilt magnetization is also indicated by the final shallow inclination.

A significant number of samples from all lithologies display characteristic magnetization directions which deviate from either the expected pretilt or posttilt directions (Figure 6). In many such samples, a discrepancy is observed between the results of $\mathrm{AF}$ and thermal demagnetization (compare Figures $6 \mathrm{a}$ and $6 \mathrm{~b}$ ). Note that the north and up component in the thermally demagnetized sample $\left(520^{\circ}-540^{\circ} \mathrm{C}\right)$ appears as the highest coercivity component in the AF sample. We suggest that this inconsistency results from the superposition of reversed and normal magnetizations which are inadequately separated by either technique. The demagnetization diagrams of the pillow lavas in Figures $6 c$ and $6 \mathrm{~d}$ illustrate that these anomalous directions (NW, up and W, up) are well-defined. The inflection in the inclination curve of $\mathrm{LP865b2}$ at $200^{\circ} \mathrm{C}$ is also typical of many samples from the Seamount Series. The consistent orientation of the low-stability component parallel to the present field direction at La Palma (e.g., Figure 6d) rules out sample misorientation as an explanation of these anomalous directions.

Results from a volcaniclastic unit (Figures 6e and 6f) suggest that these aberrant directions may be the result of alteration. The sample in Figure $6 e$ is an amoeboidal pillow which has a pretilt normal magnetization compatible with the in situ high temperature emplacement of the amoeboidal pillows in this unit [Staudigel and Schmincke, 1984]. The water-saturated matrix probably never reached temperatures $>100^{\circ} \mathrm{C}$ and may have been mechanically disturbed during pillow emplacement. Both AF and thermal demagnetization of the interstitial hyaloclastite material (Figure 6f) yield a northward and up component similar to that noted in other lithologies. These results suggest that the high glass content of the hyaloclastite has resulted in significant alteration while the amoeboidal fragment maintained its original magnetization, albeit with a significant viscous overprint. The origin of these anomalous directions will be discussed more fully below.

Blocking temperature data from the demagnetization studies also yield a first order characterization of the magnetic mineralogy. Thermal demagnetization of isothermal remanent magnetization, petrographic observations, microprobe data and Curie temperature determinations provide additional constraints on the magnetic mineralogy; however, the blocking temperature data are particularly useful since this data is 
$\mathbf{A}$

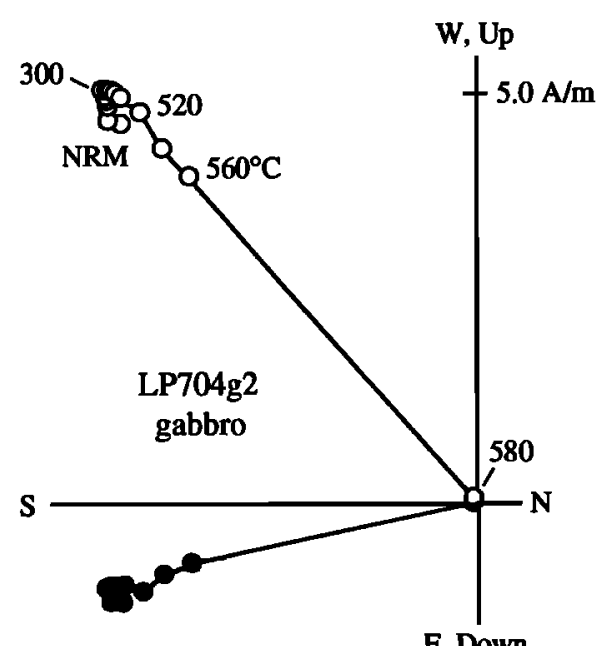

C
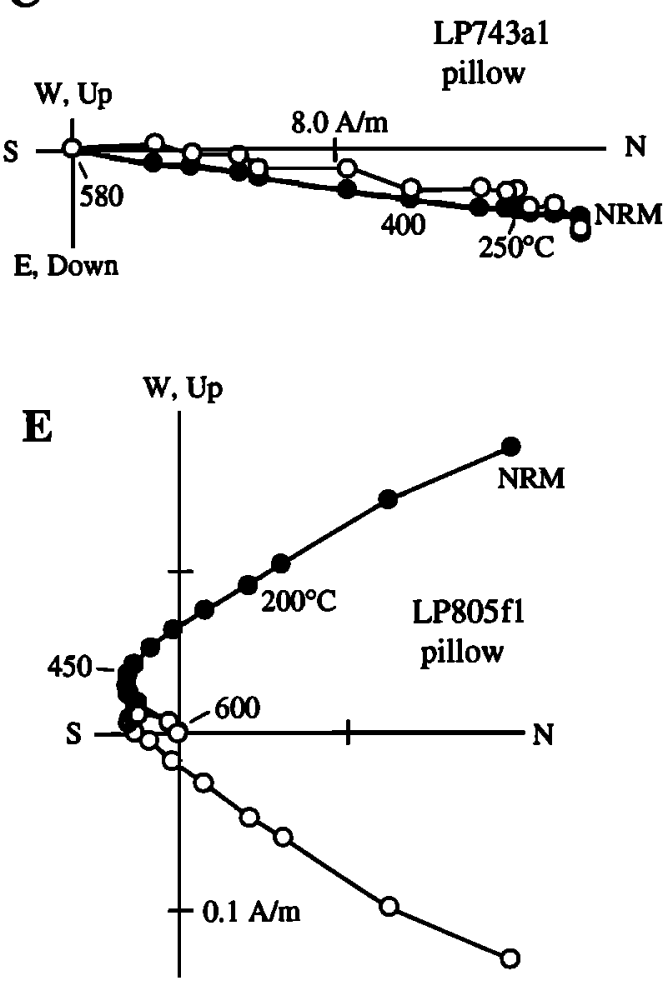

B

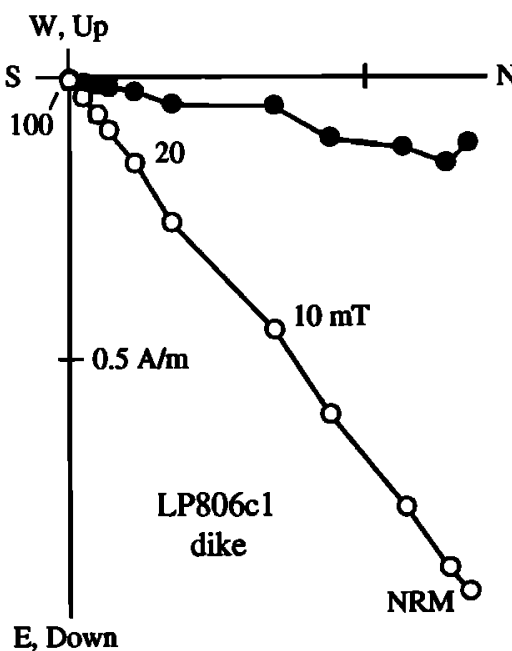

D

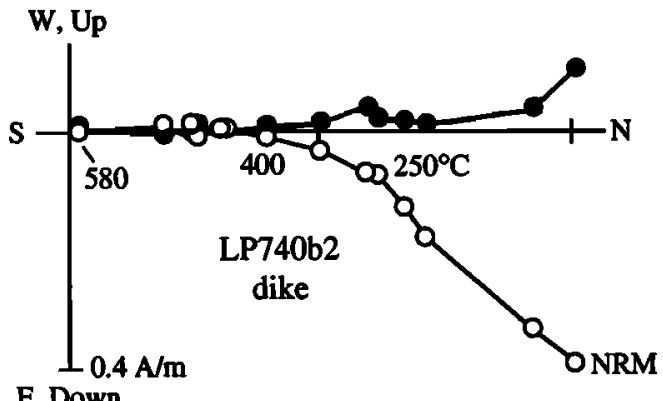

E, Down

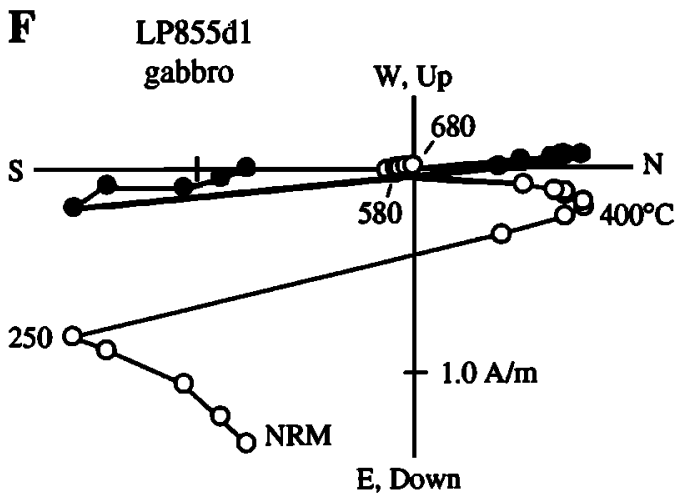

Fig. 5. Representative vector endpoint diagrams (geographic coordinates) from La Palma Nearly univectorial demagnetization in (a) reversed polarity gabbro and (b) normal polarity dike. Both directions are posttilt. (c) Normal polarity direction which predates tilting. (d) Shallow, normal polarity pretilt component with moderate low-stability component. (e) Reversed pretilt direction with substantial normal polarity overprint. (f) Complex demagnetization behavior in leucogabbro within the extrusive series. Solid (open) circles are projections of the vector onto the horizontal (vertical) plane.

universally available. We define the maximum blocking temperature ( $\mathrm{Tb}$ ) as the temperature step at which the remanent intensity drops to below $2 \%$ of the VDS intensity or the direction becomes random. Peak unblocking may, and often does, occur at a temperature $<\mathrm{Tb}$. A Tb of $<600^{\circ} \mathrm{C}$ is therefore compatible with the presence of magnetite as the remanence carrying phase, whereas higher values apparently require the presence of a higher temperature phase (hematite). The justification for, and limitations of, our mineralogical interpretation of the $\mathrm{Tb}$ data are dealt with in a later section.
Intrusives from La Palma are dominated by $\mathrm{Tb}$ near $600^{\circ} \mathrm{C}$ (Table 2). Gabbros have $\mathrm{Tb}$ ranging from $580^{\circ}-680^{\circ} \mathrm{C}$, although the majority of samples have peak unblocking over a very discrete interval $\left(540^{\circ}-600^{\circ} \mathrm{C}\right)$ compatible with the presence of magnetite. Several gabbros have a small percentage of remanence remaining at $600^{\circ} \mathrm{C}$ (up to $18 \%$ ), but in only one case (Figure $5 f$ ) is the high temperature direction distinct from the direction at temperatures $<600^{\circ} \mathrm{C}$. The majority $(74 \%)$ of dikes/sills have $\mathrm{Tb}$ between $500^{\circ}$ and $600^{\circ} \mathrm{C}$, but higher $\mathrm{Tb}$ (up to $640^{\circ} \mathrm{C}$ ) occur and are particularly 
A

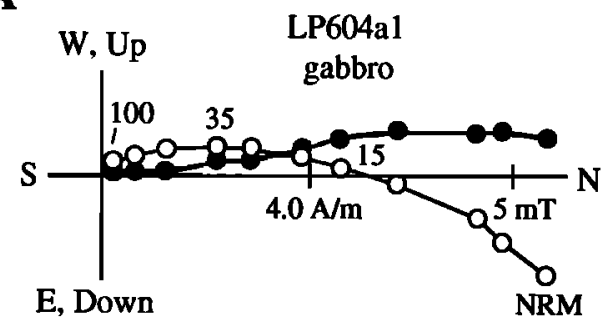

$\mathbf{C}$

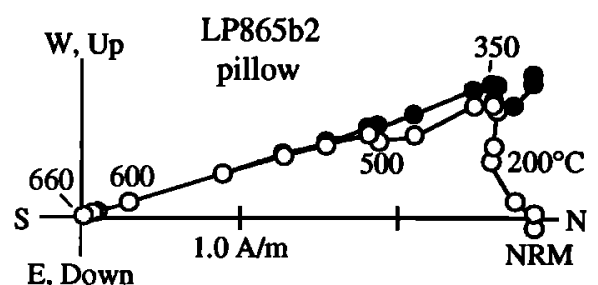

$\mathbf{E}$

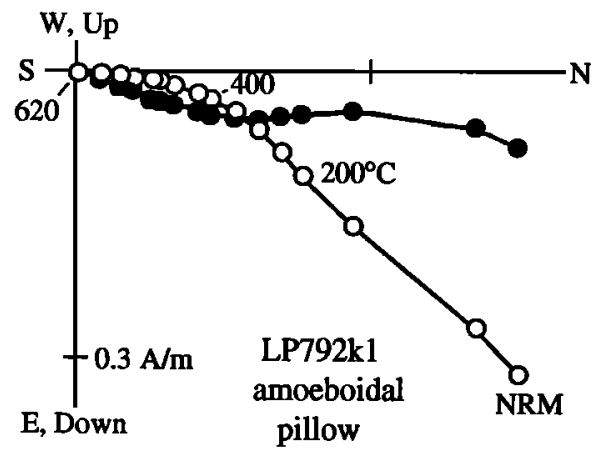

B

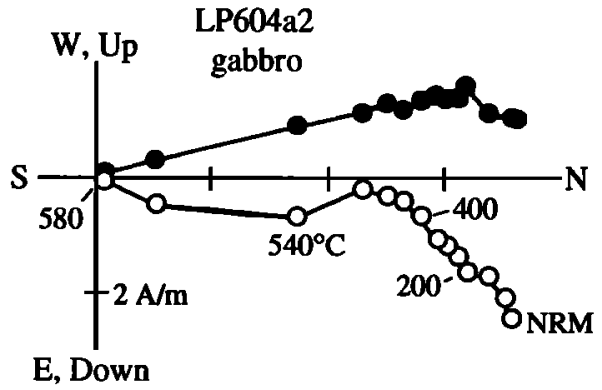

$\mathbf{D}$

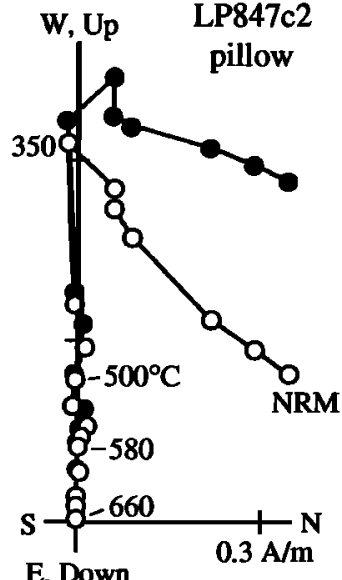

E, Down

$\mathbf{F}$ LP792c1

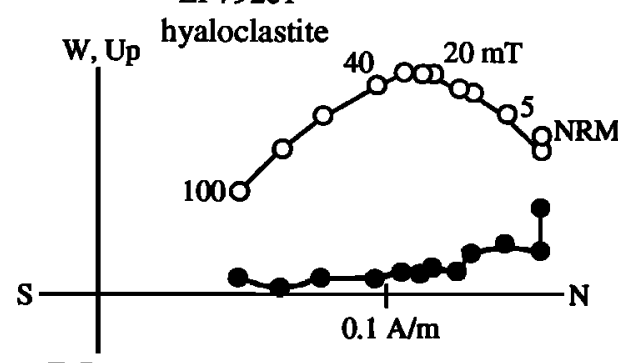

E, Down

Fig. 6. Vector endpoint diagrams illustrating anomalous remanence directions (geographic coordinates). Northward and shallow upward final direction in (a) AF-demagnetized sample corresponds to an intermediate $\left(520^{\circ}-540^{\circ} \mathrm{C}\right.$ ) component in the corresponding (b) thermally demagnetized sample. (c) Well-defined anomalous remanence direction with characteristic inflection in inclination projection at $\sim 200^{\circ} \mathrm{C}$. (d) An extreme example of an anomalous direction (W, Up) with a lowstability overprint similar to the present day field at La Palma. (e) Amoeboidal pillow fragment maintains a shallow, pretilt direction, whereas (f) the surrounding hyaloclastite shows anomalous north and up directions. Solid (open) circles are projections of the vector onto the horizontal (vertical) plane.

common in sills. In contrast to gabbro samples, dikes/sills often have a distributed blocking temperature spectrum which includes significant unblocking at temperatures of $250^{\circ}-$ $400^{\circ} \mathrm{C}$

Perhaps the most unexpected result from the study of the Seamount Series is the uniformly high $\mathrm{Tb}\left(500^{\circ}-\right.$ $680^{\circ} \mathrm{C}$ ) in pillow lavas, in view of the Ti-rich composition of primary titanomagnetite in rapidly-cooled, basic igneous rocks $\left(\mathrm{Fe}_{3-x} \mathrm{Ti}_{x} \mathrm{O}_{4}\right.$, with $0.50<x<0.85$ [Carmichael, 1967; Carmichael and Nicholls, 1967; Haggerty, 1976]). Although only one third of the samples is completely demagnetized by $600^{\circ} \mathrm{C}$, the majority of samples exhibit peak unblocking between $500^{\circ}$ and $600^{\circ} \mathrm{C}$, consistent with a remanent magnetization carried primarily by low-Ti magnetite. Some samples also have significant unblocking at temperatures in accord with a more Ti-rich titanomagnetite although a high blocking temperature phase is always present. Both Tb and the median destructive field increase with the degree of alteration (Table 2). Pillow samples from the more altered portion of the Seamount Series may have a significant amount of remanence remaining at $600^{\circ} \mathrm{C}$ (as high as 32\%) and $\mathrm{Tb}$ which extend to near the Néel temperature of hematite (e.g., Figure 6d).

\section{Low-Stability Component and Viscous Remanence}

The majority of samples from La Palma have a lowstability magnetization component of normal polarity, the magnitude of which (as a percentage of the VDS) varies considerably (Figure 7). Because the magnitude of the low-stability component is inversely correlated with the VDS, 
A
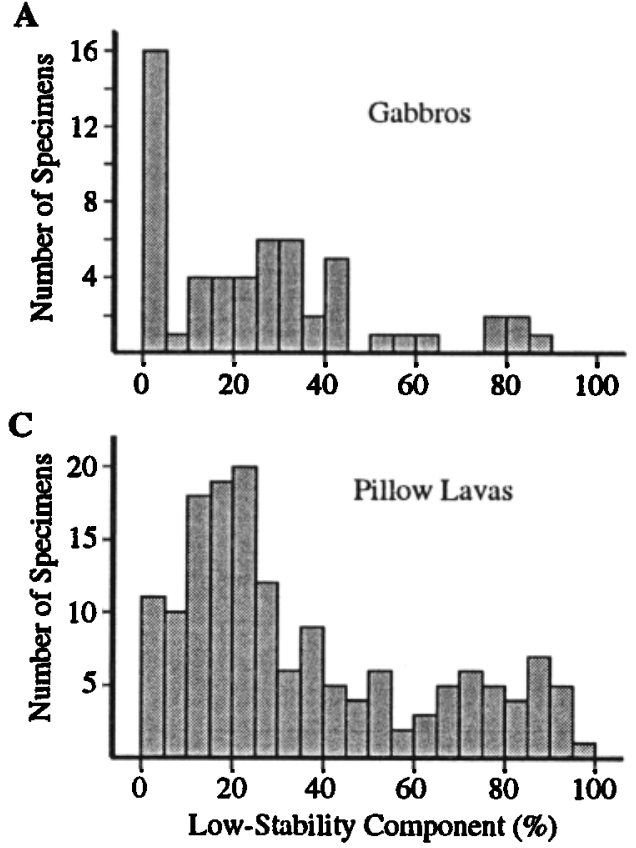

B
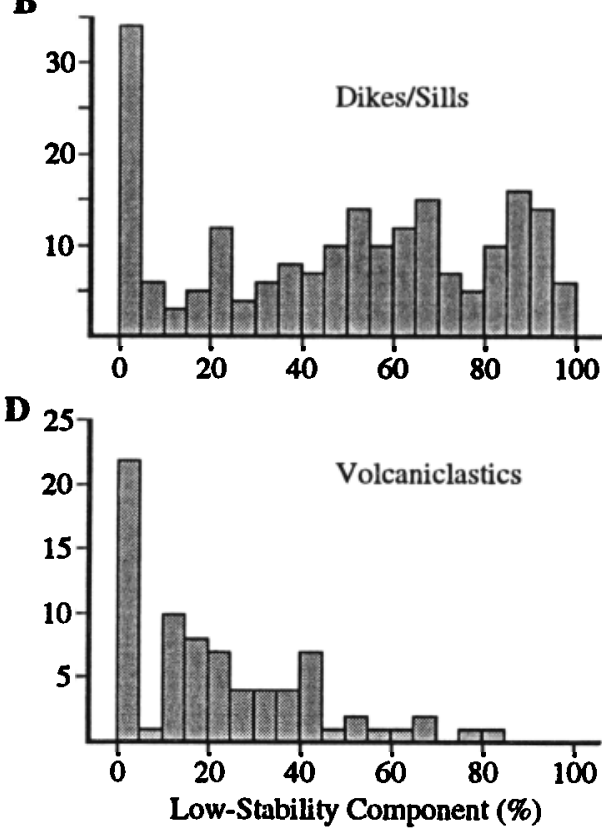

Fig. 7. Histograms of the percentage of the low-stability component of magnetization for different lithologies. The magnitude of the low-stability component is inversely relaled to the vector difference sum (VDS). The magnitude of the low-stability component weighted by the VDS provides the best estimate of the low-stability contribution for each lithology (Table 2).

a weighted mean was calculated to provide the best estimate of the low-stability contribution for each lithology (Table 2). Moderate low-stability components are common in several leucogabbros, although the majority of gabbros have relatively minor secondary overprints. The most substantial secondary magnetizations (36\%) are in dikes/sills from La Palma. Pillow lavas typically have lower percentages of secondary magnetization than do the dikes and sills; however, larger low-stability components are present in some pillow lavas, particularly those from the more highly altered portion of the sequence (Table 2). Pillow fragments and hyaloclastites also have small secondary magnetizations.

Principal component directions (maximum angular deviation $<20^{\circ}$ ) for the low-stability component of magnetization indicate that this component was acquired after tilting (Figure 8). Apart from a small number of reversed directions ( 20), which are not shown in the lower hemisphere projection in Figure 8, the distribution is compatible with a recent magnetization. The more than 600 directions in the normal mode yield a Fisherian mean of $352.3^{\circ}, 46.8^{\circ}\left(\alpha_{95}=1.8^{\circ}\right)$ which lies between the posttilt normal GAD direction and the present field direction at $\mathrm{La} \mathrm{Palma}\left(351^{\circ}, 40^{\circ}\right)$. This direction is compatible with a VRM of relatively recent origin, an interpretation generally supported by results from a laboratory viscous acquisition experiment.

The potential contribution of viscous remanence in the La Palma samples was evaluated through a VRM acquisition experiment in which 80 samples were placed in a vertical 0.1 mT ( $\pm 3 \%$ ) field for 5600 hours ( 8 months). The samples were periodically removed from the field, measured (typically less than one minute), and returned to the field. Lowfield storage and prior demagnetization are known to affect VRM acquisition in multidomain samples [e.g., Tivey and Johnson, 1984]. Therefore, the previously AF-demagnetized samples (61) were again subjected to AF demagnetization at $70 \mathrm{mT}$ immediately prior to the start of the experiment to minimize these effects. The remaining samples were in an undemagnetized state and provide a comparison between NRM and AF-demagnetized specimens from the same core.

Although some samples exhibit nearly linear VRM acquisition with respect to $\log$ (time), the majority show an increase after approximately 100 hours (Figure 9a). Such nonlinear behavior has been attributed to inhomogeneity in the grain

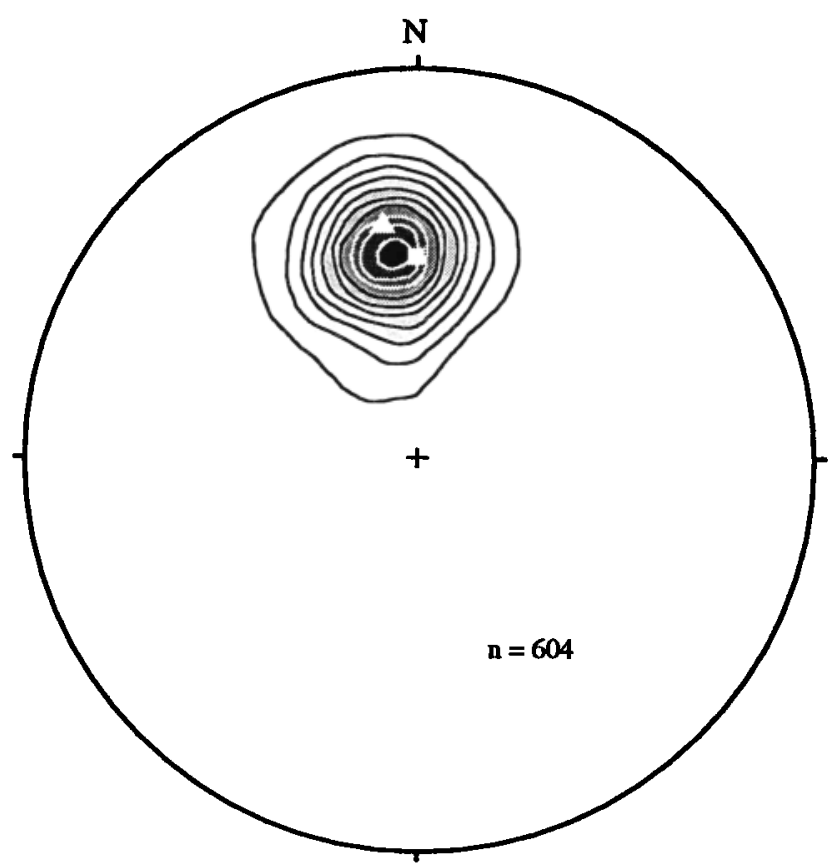

Fig. 8. Lower hemisphere equal area projection of the low-stability component from La Palma samples. Two percent isodensity contours are shown. The GAD and present field directions at La Palma are indicated by the square and triangle, respectively. 
$\mathbf{A}$

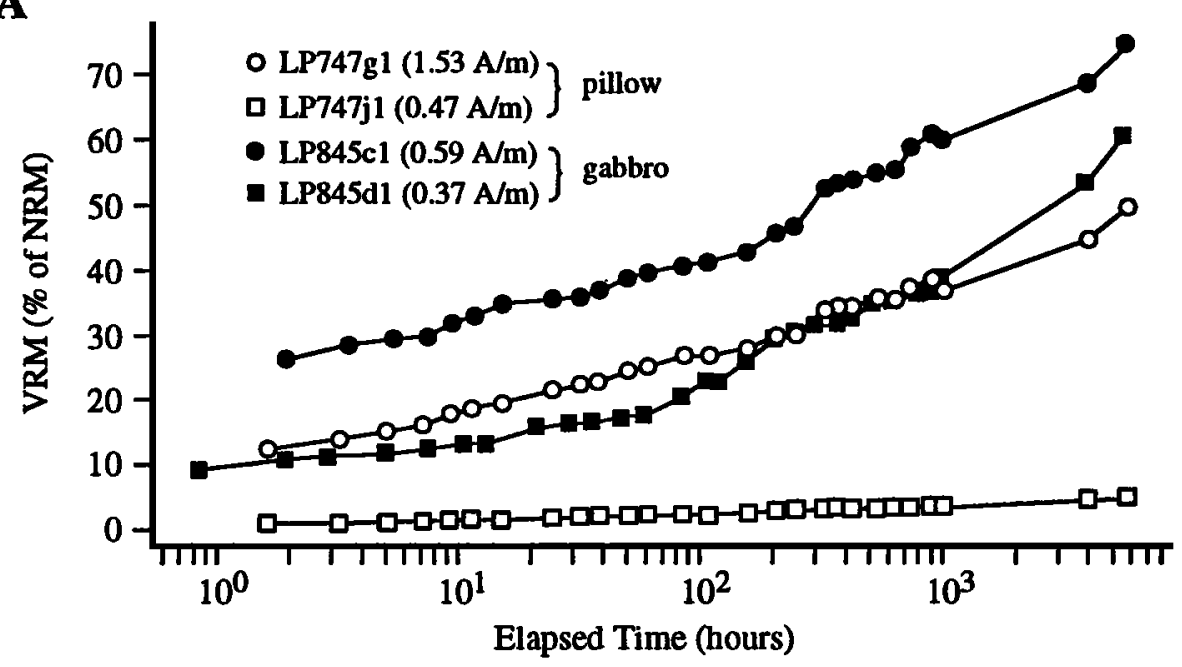

B
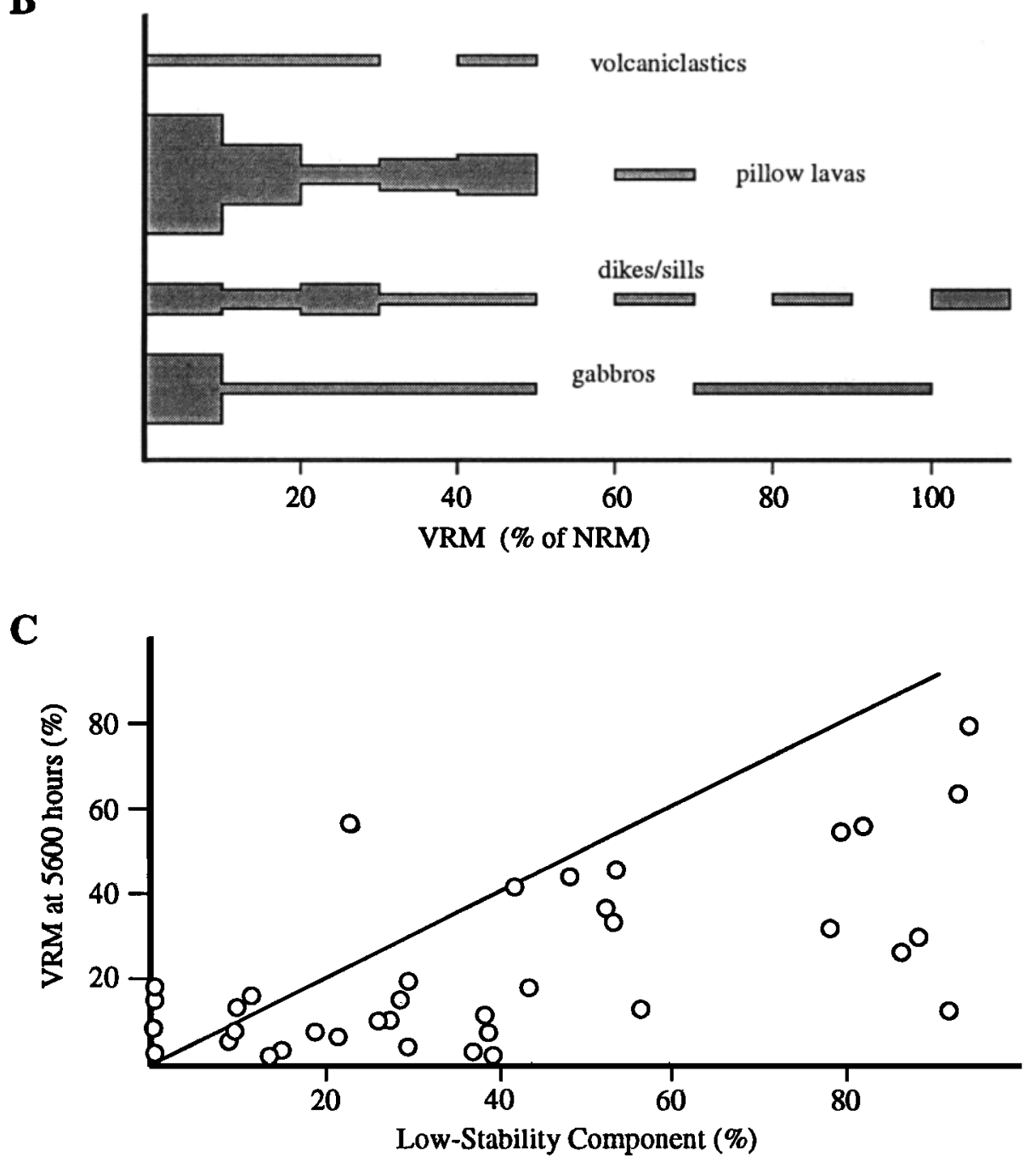

Fig. 9. Viscous remanent magnetization (VRM) in La Palma samples. (a) Representative VRM acquisition curves for La Palma samples. Note the nonlinear acquisition with respect to $\log$ (time) particularly in sample LP845. Undemagnetized sample (LP845d1) acquires lower VRM than the AF-demagnetized sample (LP845c1). Sample from the pillow interior (LP747g1) acquires a much larger VRM than the corresponding sample from the pillow margin (LP747j1). Magnitude of the VRM acquired in 5600 hours given in parentheses. (b) Summary of VRM at 5600 hours in various lithologies. The width of the line is proportional to the number of samples. (c) Comparison of viscous remanence at 5600 hours and the percentage of the low-stability component of magnetization. The measured viscous remanence has been corrected for the difference between the NRM and vector difference sum intensities as described in the text. 
size distribution or the presence of different mineralogies [e.g., Dunlop, 1983; Kent and Lowrie, 1977] and clearly renders extrapolation to geological time scales inappropriate. The VRM after 5600 hours, however, gives a minimum estimate of the low-temperature viscous contribution. In contrast to results from synthetic samples [e.g., Tivey and Johnson, 1984], the undemagnetized samples (e.g., LP845dl in Figure 9a) acquire a smaller VRM than the corresponding AF-demagnetized sample (LP845c1). This apparent inconsistency probably results from the presence of a Brunhes VRM in the undemagnetized samples from La Palma. A portion of the residual VRM will be unaffected on laboratory time scales, resulting in lower laboratory VRM for the undemagnetized samples. The two curves, however, should converge at longer time scales and we have used the results from the AF-demagnetized samples as the best estimate of the viscous contribution.

The laboratory VRM acquired by various lithologies
(Figure 9b) allows some generalizations to be made which are relevant for the magnetization of seamounts. Intrusives show a wide range of viscous acquisition from negligible to larger than the corresponding NRM. Leucocratic gabbros typically acquire a larger VRM than more mafic gabbros, a relationship which is also supported by the observation of larger VRM in the more felsic portions within a single intrusion. Significant variability in VRM acquisition was also noted within individual dikes/sills although no simple relationship was obvious. Although the VRM contribution in most pillow lavas is small (nearly $2 / 3$ have VRM $<20 \%$ ), higher viscous components do occur. The higher VRM in a pillow interior (LP747g1 in Figure 9a) relative to the margin (LP747j1) suggests that the overall contribution of VRM from the extrusives may be sensitive to such factors as average pillow size (presumably reflecting grain size differences). Hyaloclastite samples acquire a relatively small VRM component, however, the higher intensities of basalt
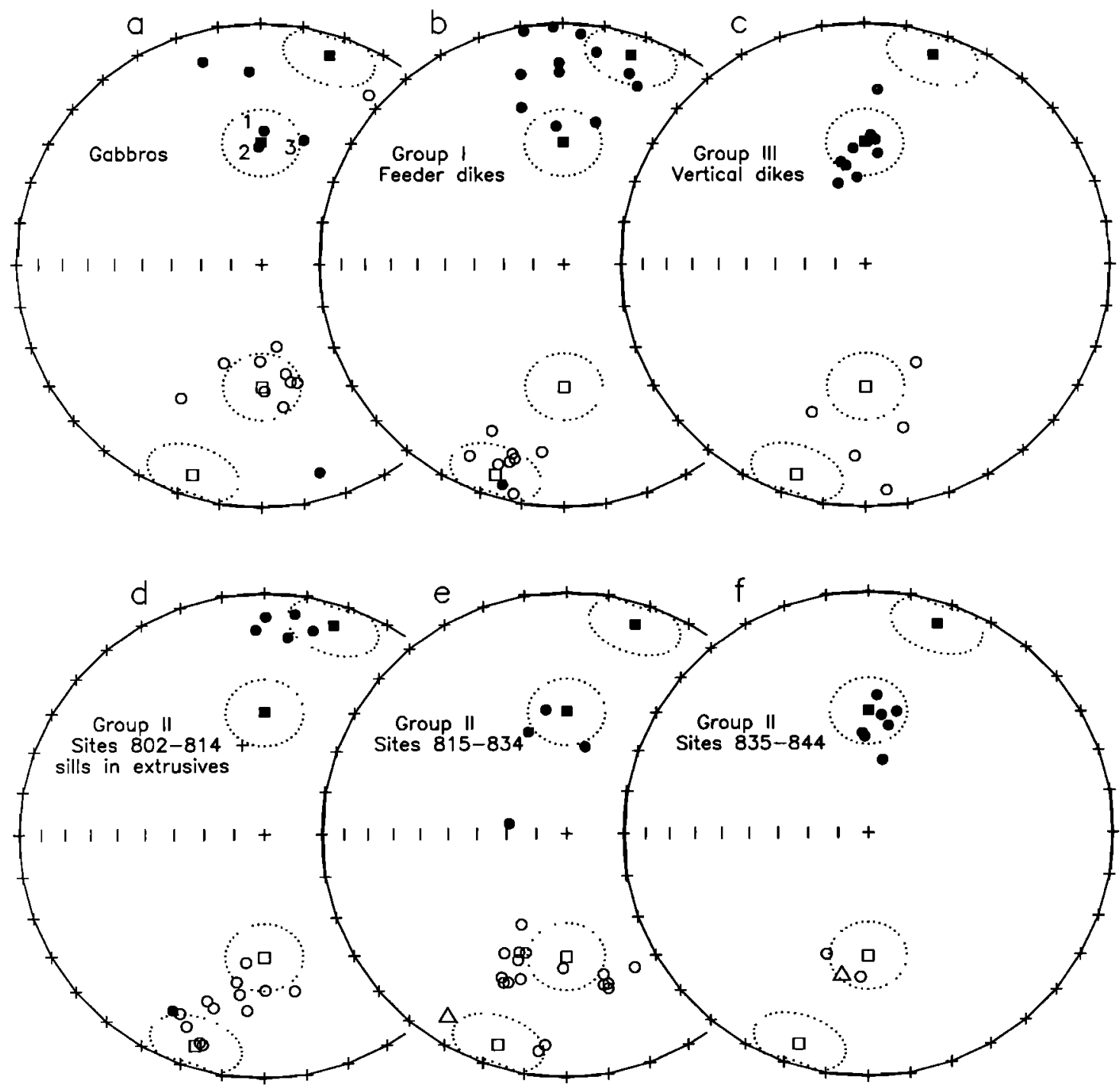

Fig. 10. Characteristic site mean remanence directions (geographic coordinates) for intrusives from La Palma. Open (solid) symbols are upper (lower) hemisphere projections. The posttilt GAD directions at La Palma $\left( \pm 48^{\circ}\right)$ and the expected pretilt normal $\left(019^{\circ}, 10^{\circ}\right)$ and reversed $\left(199^{\circ},-10^{\circ}\right)$ are shown by the squares with associated dispersion inferred from paleosecular variation studies. (a) Gabbros have predominantly posttilt directions, (b) feeder dikes for the layered extrusive series have mostly pretilt directions, and (c) vertical Group III dikes have posttilt magnetizations. (d)-(f) Sill sampling sites have a range of pretilt to posttilt directions which can best be interpreted in terms of tectonic tilting and reheating. Triangles indicate keratophyre screens within sill complex. 
fragments in breccia units suggests that a coherent signal may be produced by viscous acquisition in the clasts.

Comparison of the VRM at 5600 hours and the low-stability component determined from the thermally demagnetized sister sample (both expressed as a percentage of VDS) reveals a broad positive correlation (Figure 9c). A one to one correlation between the magnitude of the laboratory VRM and the low-stability component is not to be expected since the population of grains activated over laboratory time scales represents only a portion of the grains which would be activated since the last geomagnetic reversal. In addition, a distinct low-stability component may be undetectable in samples with a posttilt normal magnetization. Several samples exhibit very large secondary magnetizations but only small to moderate viscous remanence acquisition. The maximum blocking temperature of this component in these cases is incompatible with a simple low-temperature VRM [e.g., Pullaiah et al., 1975]. Since VRM acquisition is enhanced at higher temperatures [e.g., Dunlop, 1973], the low-stability component in these samples may represent a VRM acquired at elevated temperatures. Both the high erosion rate in the Barranco de las Angustias and the proximity to present hydrothermal activity in the caldera suggest that samples, particularly from the lower part of the Seamount Series, may have experienced elevated temperatures during the Brunhes. These data are therefore generally compatible with a viscous origin for the low-stability component, either at ambient or slightly elevated temperatures.

\section{Characteristic Magnetization Directions}

Sixty percent of the gabbro sites from La Palma have reversed directions consistent with a posttilt magnetization (Figure 10a). Two gabbros (labeled 1,2 in Figure 10a) and a gabbro screen ( 3 in Figure 10a) within the sheeted sill complex have unambiguous posttilt normal polarity directions. These two gabbro sites are in the southeast portion of the Caldera de Taburiente, the location of the present center of intrusive activity. The low laboratory viscous acquisition in these samples rules out VRM as an explanation for their normal polarity, and suggests they are relatively recent (Brunhes) intrusions. The four shallow directions in Figure 10a are all from sites within the sheeted sill complex or the extrusives and are most compatible with a pretilt magnetization. Excluding these four sites, the mean directions in geographic coordinates for the reversed $\left(179.5^{\circ},-50.6^{\circ} ; \mathrm{n}=9, \alpha_{95}=7.8^{\circ}\right)$ and normal polarity gabbro sites $\left(006.5^{\circ}, 46.5^{\circ} ; \mathrm{n}=3, \alpha_{95}\right.$ $=8.1^{\circ}$ ) are statistically indistinguishable from the expected posttilt directions.

Feeder dikes (Group I) for the extrusives have directions generally compatible with a pretilt magnetization (Figure 10b). The reversed polarity directions (mean $196.3^{\circ},-14.6^{\circ} ; \mathrm{n}=$ $9, \alpha_{95}=6.7^{\circ}$ ) cluster close to the expected pretilt direction whereas the normal polarity directions are distributed between the pretilt and posttilt directions and include some shallow northwesterly directions. The normal polarity directions near the posttilt direction may be viscous based on the high percentage of VRM (up to $105 \%$ of NRM) acquired over 5600 hours. Contamination by an unremoved present field component, however, cannot explain the anomalous northwesterly directions. We will demonstrate below that these northwesterly directions are probably the result of a reversed remagnetization event prior to tilting of the Seamount Series.
Vertical (Group III) dikes have posttilt directions in accord with the young ages determined isotopically and inferred from crosscutting relationships (Figure $10 \mathrm{c}$ ). The normal polarity samples have a mean $\left(357.6^{\circ}, 50.5^{\circ} ; \mathrm{n}=10, \alpha_{95}=5.8^{\circ}\right)$ which is indistinguishable from the posttilt direction. VRM data from a single normal polarity Group III dike suggests that the normal polarity cannot be ascribed entirely to viscous magnetization. The reversed polarity samples have poorly defined characteristic magnetization directions as a result of substantial low-stability components (Table 2) and the site means are often calculated from great circle intersections. The great circle paths during demagnetization all pass through the posttilt reversed direction and are compatible with a posttilt magnetization.

The characteristic magnetization directions of sills (Group II) include pretilt, posttilt and intermediate directions. Site mean directions for sills from within the layered extrusive series and the detailed sill sampling site furthest from the caldera (sites 802-814; see Figure 1a) are shown in Figure 10d. Sills from within the extrusives are dominantly of normal polarity and have directions consistent with a pretilt magnetization. The remaining sills are almost exclusively of reversed polarity and include directions between the pretilt and posttilt directions. Sills from sites 815-834 (Figure 10e) are also dominantly of reversed polarity, with most directions closest to the expected posttilt GAD direction. Two sills and a keratophyre (altered trachyte) screen at this locality have shallower, apparently pretilt reversed directions and a small number of posttilt normal directions are also present. The sills (and a single keratophyre) sampled closest to the caldera (sites 835-844) have exclusively magnetizations acquired after tilting (Figure 10f). Although the sills at this site are predominantly of normal polarity, VRM acquisition experiments eliminate viscous remanence as a likely explanation for the observed posttilt direction.

Magnetizations in La Palma extrusives which clearly postdate tilting are rare, as indicated by the scarcity of directions near the GAD normal direction in Figure 11a. The origin of posttilt magnetizations in these extrusives can be attributed to a low-temperature VRM in some cases (as inferred from large laboratory VRM) or to chemical remagnetization as suggested by hematite $\mathrm{Tb}$. The majority of pillow sites are of normal polarity, but have directions in geographic coordinates (Figure 11a) which are generally to the west of the expected pretilt direction and include many negative inclinations. After tilt correction these normal polarity directions form a broad swath consistent with great circle paths from the reversed pretilt direction (Figure 11b). In contrast, the reversed polarity pillow lavas yield a tilt-corrected mean $\left(180.6^{\circ},-53.1^{\circ} ; \mathrm{n}=7, \alpha_{95}=\right.$ $10.1^{\circ}$ ), indistinguishable from the expected pretilt direction. This distribution is suggestive of a reversed remagnetization which predates tilting of the Seamount Series. Incompletely separated present field components, on the other hand, cannot account for the shallow northwesterly directions. Normal polarity directions along such remagnetization circles would be confined to nearly constant inclinations of about $50^{\circ}$ in tilt-corrected coordinates.

Results from volcaniclastic units in the La Palma Seamount Series generally support the proposition of a nonmagnetic carapace on seamounts [e.g., Harrison, 1971; Harrison and Ball, 1975]. The majority of pillow fragment breccias have clasts with random magnetization directions, consistent 

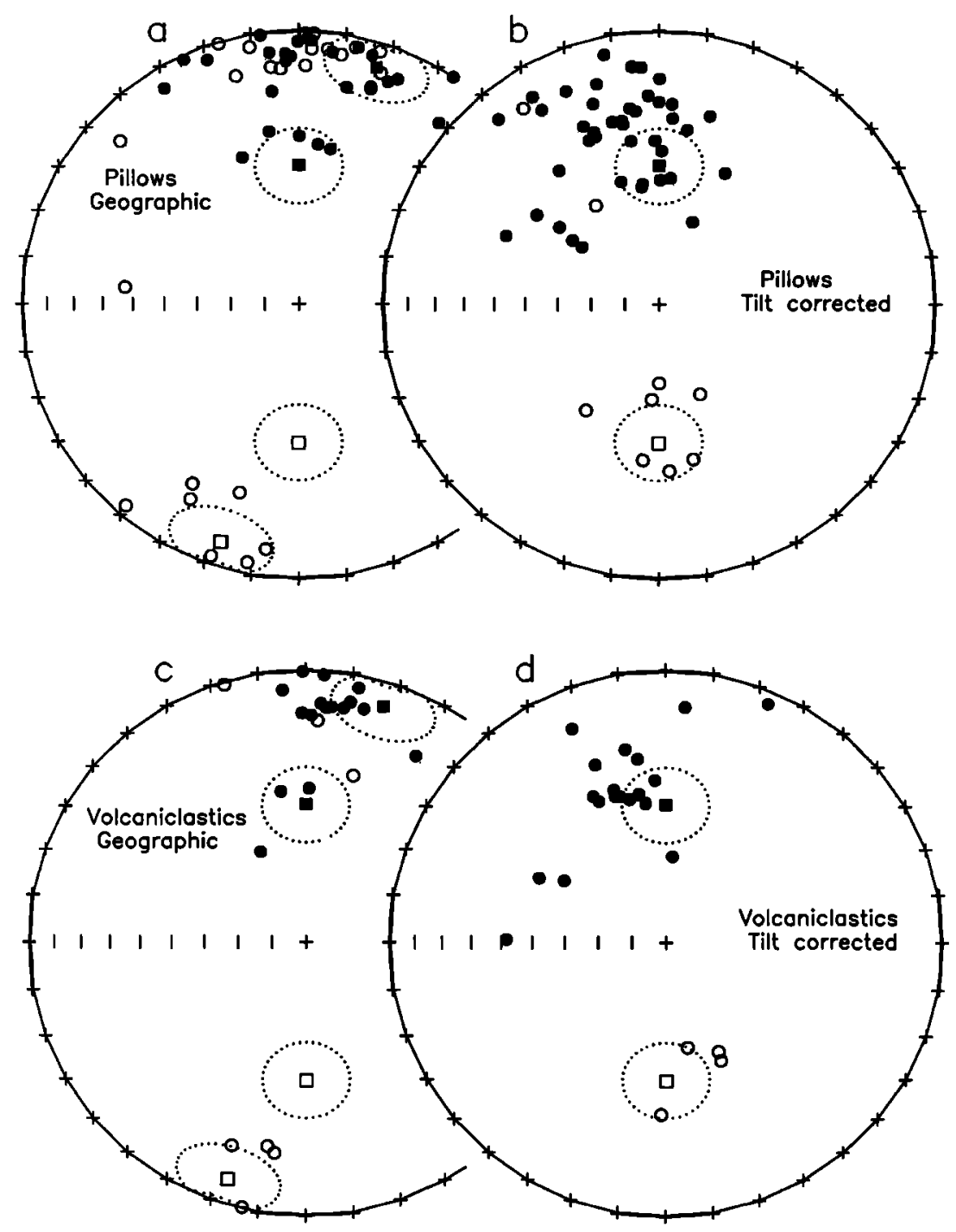

Fig. 11. Characteristic site mean remanence directions in geographic and tilt-corrected coordinates for (a and b) pillow lavas and (c and d) volcaniclastic units from La Palma. Symbols as in Figure 10. Note the band of northwesterly and shallow normal polarity directions after tilt correction compared to the well clustered reversed polarity directions.

with an origin by fragmentation and redeposition inferred from clast rounding [Staudigel and Schmincke, 1984]. The interstitial hyaloclastite material (ash- or lapilli-sized glassy material) in pillow fragment breccias, however, often yields a consistent direction which predates tilting. Lapillistones also record a pretilt magnetization direction although the overall contribution of such units to seamount magnetic anomalies is likely to be small. Submarine scoriaceous breccias have consistent pretilt directions in both the fragments and the hyaloclastite material. These data essentially confirm the interpretation of Staudigel and Schmincke [1984] that the scoriaceous pillows/breccias are in situ deposits which have not been displaced subsequent to their emplacement.

In Figures $11 \mathrm{c}$ and 11d we plot site means for volcaniclastic sites with coherent directions as well as directions of individual hyaloclastite cores from sites with random clast magnetization directions. The majority of the sites have directions most consistent with a pretilt magnetization. Once again, the normal polarity directions in geographic coordinates lie to the west and are shallower than the expected direction, suggesting an incompletely removed reversed component of magnetization (Figure 11c). The consistency of individual hyaloclastite cores and the site mean directions suggests the higher permeability hyaloclastites are preferentially remagnetized even when the clasts retain their original (random) magnetization directions (compare Figures $6 e$ and $6 f$ ). A small number of posttilt normal directions are also evident in Figure 11c. In many cases, this magnetization can be ascribed to reheating from an adjacent Group III dike although moderate laboratory VRM is observed in some hyaloclastite samples.

\section{Discussion}

The results from La Palma samples (Table 2) suggest that remanence acquisition processes within seamounts may be complex. The NRM of La Palma samples provides a poor estimate of the characteristic magnetization direction, indicating that preservation of a simple thermoremanent magnetization (TRM) acquired during seamount construction is probably rare. Viscous remanence experiments and the magnitude of the low-stability component document the importance of later VRM. Furthermore, the uniformly high $\mathrm{Tb}$ and the presence of anomalous remanence directions in the Seamount Series may be indicative of significant 
chemical remagnetization. An understanding of the magnetic mineralogy and origin of these anomalous directions is critical to evaluating to what extent an original TRM may be preserved within the Seamount Series.

\section{Magnetic Mineralogy}

We interpret the uniformly high Tb in the Seamount Series to indicate the presence of Ti-poor titanomagnetite in both intrusives and extrusives. The presence of nearly pure magnetite in intrusives might be expected simply from their slow cooling history, however, its presence in the extrusives is enigmatic. The dominance of $\mathrm{T}_{1}$-poor magnetite is strongly supported by the petrographic observations and magnetic data outlined below. In addition, we use the percentage of remanence remaining at $600^{\circ} \mathrm{C}$ as an indicator of the possible contribution of hematite to the remanence. The inferred hematite contribution is less certain, but is also generally supported by the available data. We attribute both

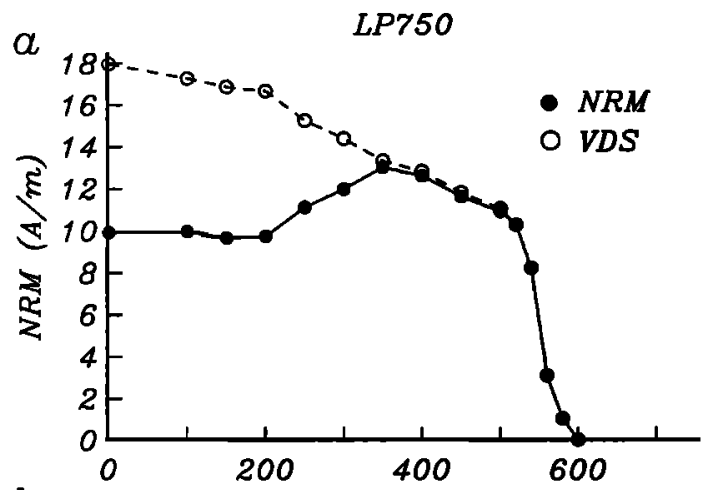

b

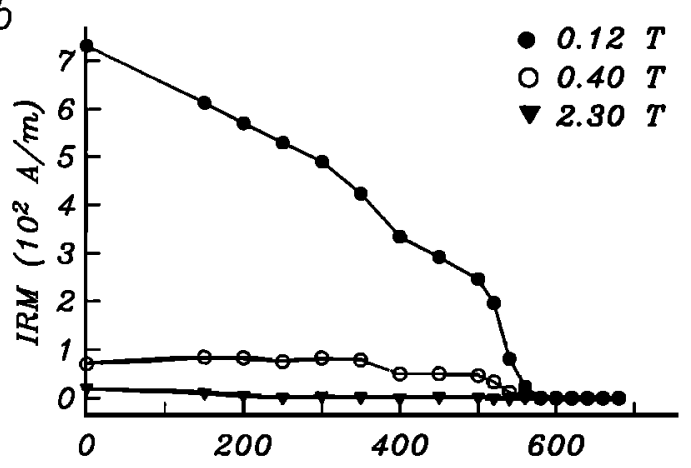

C

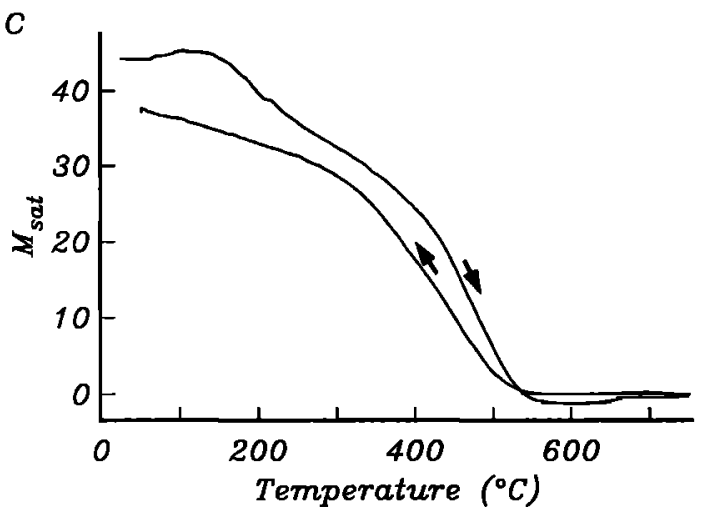

the production of low-Ti magnetite and hematite in extrusives to hydrothermal alteration processes.

A sample from the uppermost portion of the Seamount Series illustrates the dominance of the low-Ti spinel phase even in relatively unaltered pillows (Figures 12a-12c). Microprobe analyses indicate a restricted range $(x=0.65)$ for the optically homogeneous titanomagnetite in this sample and imply a Curie temperature of $\sim 150^{\circ} \mathrm{C}$ [O'Reilly, 1984]. Following a technique described by Lowrie [1990], selected samples from La Palma were given an isothermal remanence (IRM) in three orthogonal directions in fields of $2.3,0.4,0.12 \mathrm{~T}$ and then thermally demagnetized. Neither the thermal decay of the NRM (Figure 12a) nor of the IRM (Figure 12b) in this sample shows any indication of unblocking temperatures consistent with the measured titanomagnetite composition. The decay of the IRM is dominated by the $0.12 \mathrm{~T}$ fraction, with essentially no contribution from the highest coercivity axis, suggesting the high blocking temperatures are not the result of hematite. The Curie temperature curve (obtained from a vertical balance

$d$

LP846
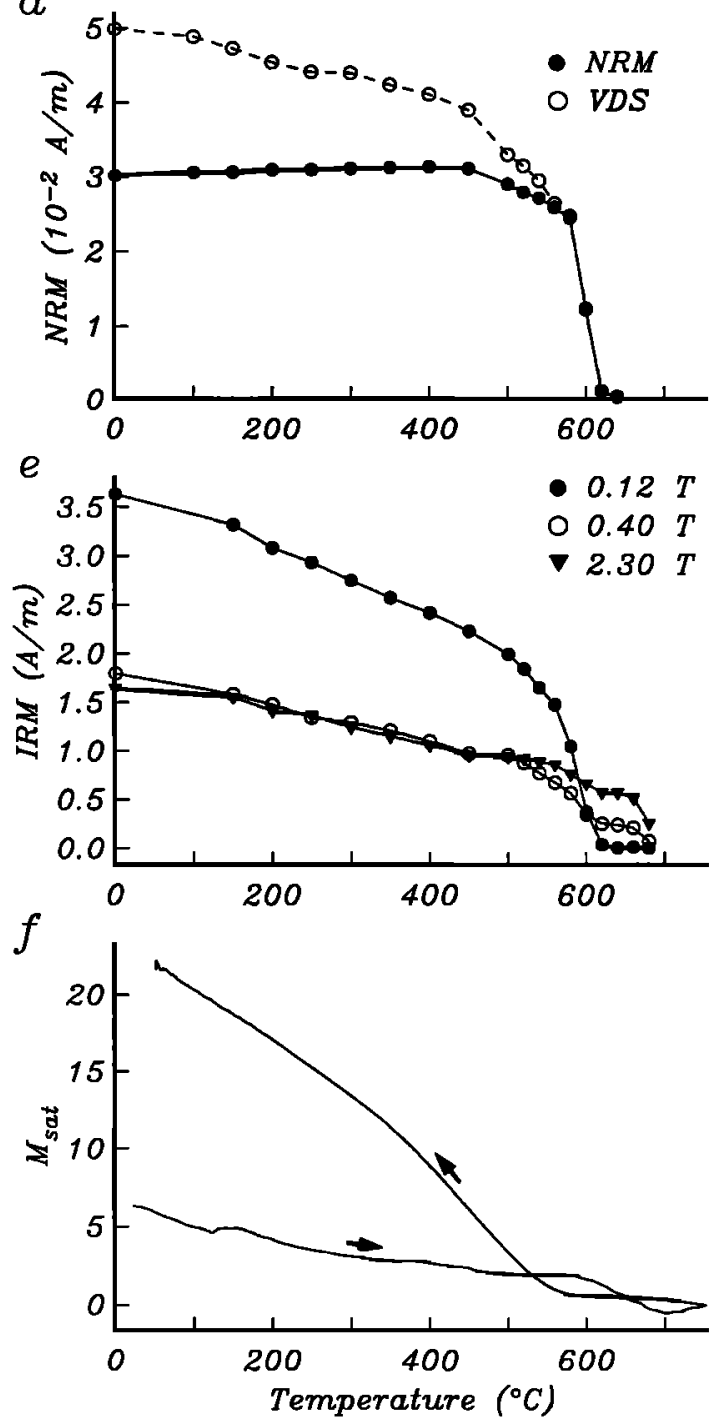

Fig. 12. Magnetic data illustrating the interpretation of blocking temperature data in terms of mineralogy. Thermal decay of (a) NRM and VDS, (b) composite IRM, and (c) Curie temperature curve for pillow sample from relatively unaltered portion of Seamount Series indicate dominance of a low coercivity, high blocking temperature component. (d)-(f) Corresponding data from highly altered pillow lava. A significant contribution from hematite for the sample in Figures $12 \mathrm{~d}-12 \mathrm{f}$ is inferred from the high blocking temperature of the NRM and the isothernal remanence. 
in an $\mathrm{Ar}$ atmosphere) is nearly reversible with a initial Curie temperature above $500^{\circ} \mathrm{C}$ and also shows little evidence of a Ti-rich titanomagnetite (Figure 12c).

These observations are consistent with the production of low-Ti magnetite by hydrothermal alteration even at the relatively low temperatures documented for the upper portion of the Seamount Series. Rapid cooling of the pillows effectively rules out deuteric oxidation as a mechanism for producing the pure magnetite. Similarly, the preservation of near equilibrium $(x=0.6)$ titanomagnetites in the least altered parts of the Seamount Series indicates that the Tipoor magnetite is probably not a primary phase in these alkalic lavas. Low-temperature oxidation of titanomagnetite may increase $\mathrm{Tb}$, however, even complete oxidation of titanium-rich titanomagnetites is insufficient to produce the observed blocking temperature spectrum [e.g., O'Reilly, 1984]. Furthermore, the isolation of the same components by $\mathrm{AF}$ and thermal demagnetization in many samples precludes artificial generation of the high $\mathrm{Tb}$ component during laboratory heating. For example, AF demagnetization of samples from site 805 (Figure 5e) recover the same pretilt reversed characteristic magnetization direction, which is isolated at temperatures of $>500^{\circ} \mathrm{C}$. Finally, microprobe analyses from more than 50 pillow sites document the production of Tipoor titanomagnetite. Titanomagnetite compositions in the upper part of the extrusive series are uniformly Ti-rich $(0.40<x<0.68)$, whereas samples from more altered regions exhibit a range of compositions which includes nearly Ti-free magnetite [Pick and Gee, 1991]. Thus, we propose that the uniformly high $\mathrm{Tb}$ in the La Palma extrusives are the result of hydrothermal alteration.

Previous authors have recognized that iron titanium oxides are sensitive indicators of the degree of hydrothermal alteration. For example, Ade-Hall et al. [1971] noted a characteristic granulation of titanomagnetite and an increase in Curie temperature even in grains without microscopic evidence of alteration. Subsequent studies have confirmed the latter observation (e.g., Iceland [Steinthorsson and Sveinbjörnsdottir, 1981], Hole 504B [Smith and Banerjee, 1986]). Both experimental [e.g., Johnson and Merrill, 1973; Ryall and Ade-Hall, 1975] and observational results [Fujimoto and Kikawa, 1989] suggest that low-Ti magnetite can be produced from titanomaghemite decomposition at temperatures as low as $150^{\circ} \mathrm{C}$. Furthermore, Hall and Fisher [1987] have documented the importance of nearly pure secondary magnetite, which occurs as pseudomorphs after original titanomagnetite, in the Troodos ophiolite. Our results from La Palma are compatible with the breakdown of titanomaghemite (titanomagnetite) to low-Ti magnetite during hydrothermal alteration. Samples from the upper portion of the Seamount Series have optically homogeneous titanomagnetite $(0.4<x<0.68)$ but $\mathrm{Tb}$ indicative of pure magnetite, suggesting submicroscopic subdivision of the original grains. More highly altered basalts often exhibit a range of ulvöspinel contents which includes nearly pure magnetite.

We suggest the percentage of the remanence remaining at $600^{\circ} \mathrm{C}$ provides an indication of the importance of hematite. Calibration tests of our Schonstedt thermal demagnetizer indicate a significant thermal gradient $\left(\sim 20^{\circ}\right)$ at high temperatures; however, the sample interior temperatures apparently equal or exceed the oven set point for temperatures of $600^{\circ} \mathrm{C}$ and above. Thus, the percent remanence remaining at $600^{\circ} \mathrm{C}$ probably provides a reasonable estimate of the presence of hematite although small percentages $(<5 \%)$ may result from noise in the demagnetization data. This estimate is not intended as a representation of the volume fraction of hematite, however, since hematite may have significant unblocking below $600^{\circ} \mathrm{C}$ and because its saturation magnetization is almost two orders of magnitude less than that of magnetite [O'Reilly, 1984].

Two thirds of pillow samples have $\mathrm{Tb}$ greater than $600^{\circ} \mathrm{C}$. With one exception (LP846 in Figure 12), however, thermal demagnetization of IRM reveals no significant high coercivity component with blocking temperatures above $600^{\circ} \mathrm{C}$, suggesting the remanence is dominated by low-Ti magnetite. LP846 is from the most altered portion of the Seamount Series (Figure 1a) and has a northwestward and up characteristic magnetization. Petrographic observations reveal little magnetic material, and hematite is apparently the only phase present. The presence of hematite (as well as some magnetite) is confirmed by demagnetization of the IRM (Figure 12e). The percentage of the IRM remaining at $600^{\circ} \mathrm{C}$ is similar to that estimated from the decay of the NRM (15-25\% for site 846), lending credence to the method of estimating hematite contribution. Hematite is also suggested by the Curie temperature determination although the low magnetization and weight loss correction make the results somewhat ambiguous.

The distribution of hematite in pillow lavas from the Seamount Series, as determined by the percentage of remanence remaining at $600^{\circ} \mathrm{C}$, is also consistent with an origin during hydrothermal alteration (Figure 13). Data from the analcime zone are limited by the dominance of volcaniclastic units in this region; however, there is a general increase in hematite contribution with degree of alteration. The distribution of hematite identified in thin section also generally confirms this result. Hematite in Seamount Series basalts occurs primarily as discrete prismatic grains presumably of hydrothermal origin [Ramdohr, 1969]. Martitization of magnetite has been reported from hydrothermally altered lithologies [e.g., Hall and Fisher, 1987; Fujimoto and Kikawa, 1989], although the presence of discrete hematite grains is apparently less common.

The magnetic mineralogy of intrusives from La Palma is more straightforward. Peak unblocking temperatures $\left(540^{\circ}-\right.$ $600^{\circ} \mathrm{C}$ ) in gabbros are consistent with the observation of oxyexsolution of ilmenite from titanomagnetite in all samples. Hematite occurs as an oxidation product of ilmenite lamellae as well as a secondary alteration product in cracks and may account for the small percentage of remanence remaining at $600^{\circ} \mathrm{C}$. Thermal demagnetization of the three axis IRM, however, reveals no significant amount of high coercivity minerals such as hematite. Thus, the volumetric contribution of hematite is apparently below the detection limit of this technique and the remanence is apparently dominated by low-Ti magnetite.

Dikes and sills from La Palma are also dominated by pure magnetite, although titanomagnetite and hematite are also present. The dominance of $\mathrm{Tb}$ between $500^{\circ}$ and $600^{\circ} \mathrm{C}$ in dikes and sills suggests the ubiquitous presence of $\mathrm{Ti}$-poor magnetite. In contrast to the gabbros, ilmenite oxyexsolution from titanomagnetite is relatively rare in La Palma dikes and sills. Rather most grains exhibit alteration to sphene or granulation similar to that noted by Ade-Hall et al. [1971] suggesting that the magnetization carried by low-Ti magnetite results from hydrothermal alteration [e.g., Hall et al., 1987; Fujimoto and Kikawa, 1989]. Substantial unblocking at much 


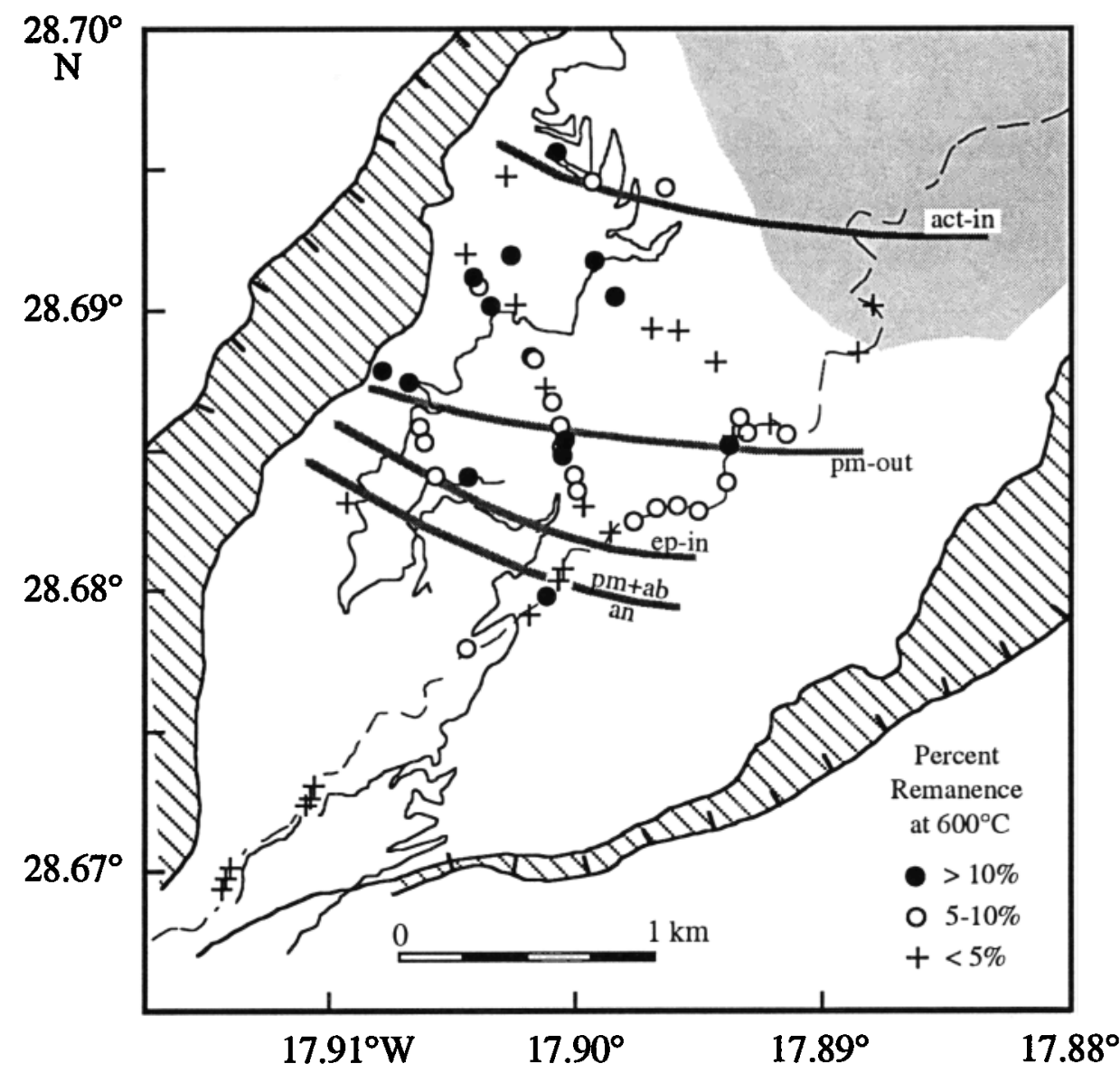

Fig. 13. Hematite contribution as inferred from the remanence remaining at $600^{\circ} \mathrm{C}$ in pillow sites from La Palma. Each point is the average of the inferred hematite contribution in several samples. Percentages $<5 \%$ may arise from noise within the demagnetization data. Other symbols as in Figure 1.

lower temperatures in many dikes/sills is compatible with the presence of residual titanium-rich titanomagnetite. This interpretation is confirmed by demagnetization of the low and intermediate coercivity axes of the IRM in these samples at temperatures of $250^{\circ}$ to $400^{\circ} \mathrm{C}$. Even in samples with a moderate hematite contribution, thermal demagnetization of the IRM reveals no high coercivity phase with blocking temperatures above $600^{\circ} \mathrm{C}$. Hematite occurs most often as discrete prismatic grains but is also present as an alteration product of ilmenite.

\section{Origin of Anomalous Remanence Directions}

It is evident from both the demagnetization curves in Figure 6 and the distribution of site mean directions (Figures 10 and 11) that a significant portion of the samples have directions which differ from either the expected pretilt or posttilt directions at La Palma, lying outside the range of directions predicted from the magnitude of paleosecular variation at this latitude. The following generalizations may be made concerning these anomalous directions: (1) normal polarity directions show higher dispersion than reversed directions, (2) normal polarity directions (in geographic coordinates) are biassed toward the west and include negative inclinations, and (3) many demagnetization diagrams show a characteristic inflection at $\sim 200^{\circ} \mathrm{C}$ (e.g., Figure 6c). The distribution of reversed site means from the sills (Figures $10 \mathrm{~d}-10 \mathrm{f}$ ) is an obvious exception to the first point and is probably best understood in terms of successive tectonic tilting and/or reheating. We propose that the anomalous directions are the result of overlapping normal and reversed polarity magnetizations which can best be attributed to a reversed remagnetization event which affected much of the Seamount Series prior to tilting.

Results from a leucogabbro within the layered extrusives illustrate how the inflection and shallow negative inclinations may be produced (Figure 14). Thermal demagnetization (Figure 14a) reveals three components, of which the lowest stability component is viscous since the sample acquired $75 \%$ VRM in 5600 hours. Indeed, the NRM is indistinguishable from the present field at La Palma (Figure 14c), confirming this component is of quite recent origin. The second component has a southerly declination and positive inclination, and the final two demagnetization steps give a direction of $035^{\circ},-22^{\circ}$ in geographic coordinates. On an equal area projection (Figure 14c), these three components are distributed along two great circles. Removal of the loweststability component gives directions along an arc away from the present field. Upon further demagnetization, the directions follow a second great circle path from the expected pretilt reversed direction towards the pretilt normal direction. The final component is most compatible with a pretilt normal magnetization although the negative inclination of this component probably indicates inadequate separation of the reversed and normal polarity components. These data suggest that this leucogabbro experienced an early remagnetization during a reversed polarity interval, and that 


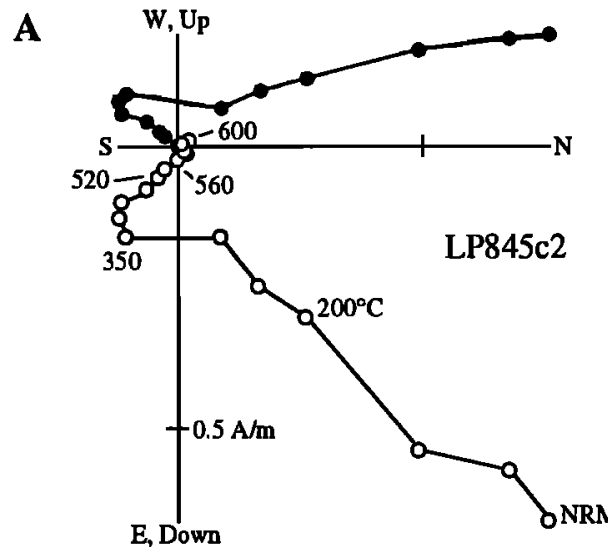

$\mathbf{B}$
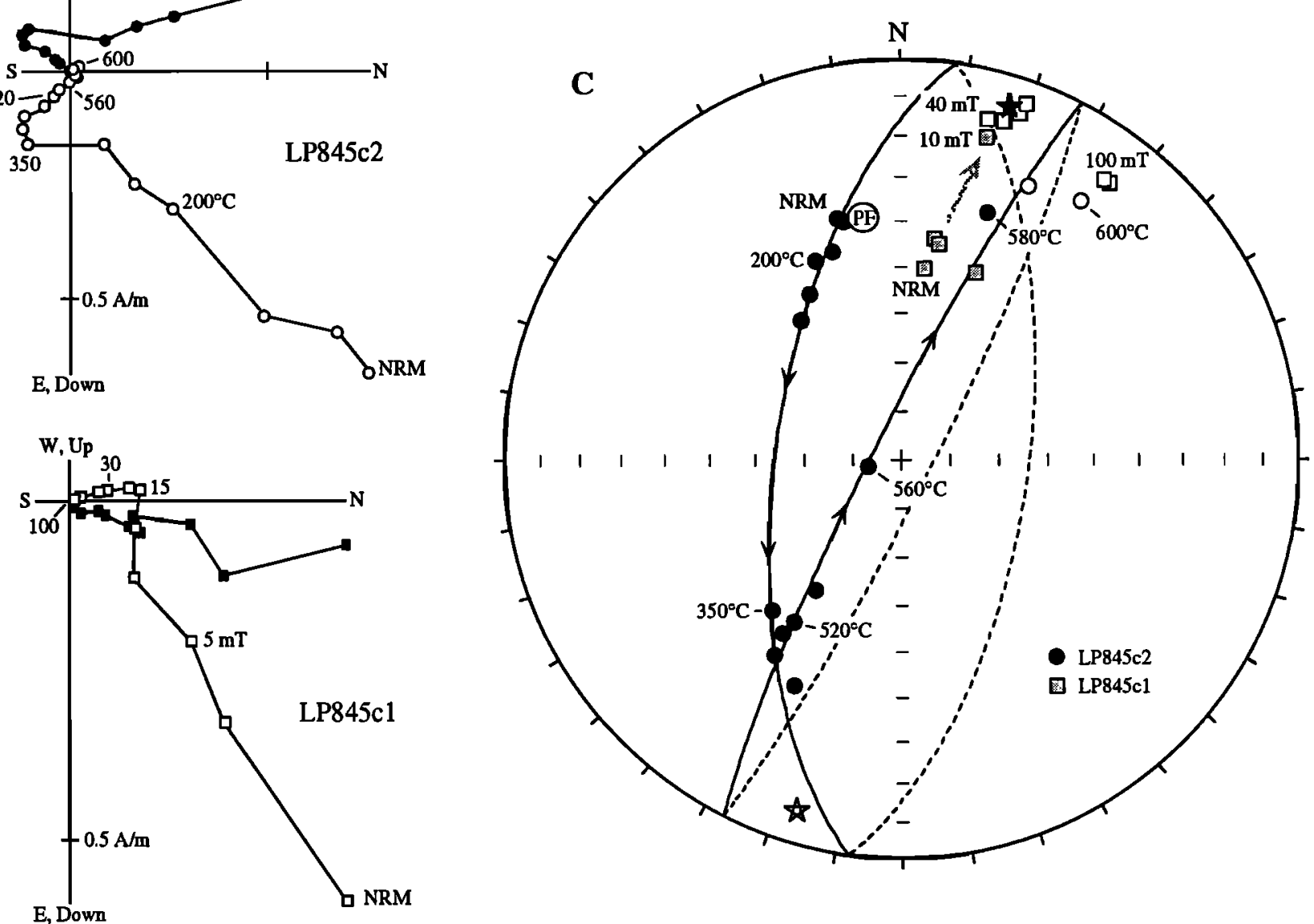

Fig. 14. Origin of anomalous characteristic remanence direction in leucogabbro. Vector endpoint diagrams for (a) thermal and (b) AF demagnetization. Solid (open) symbols are projections of the vector onto the horizontal (vertical) plane. (c) Equal-area projection of demagnetization data. Solid (open) symbols are lower (upper) hemisphere projections. Note that vectors from Figure 14a lie on two great circle paths, an initial arc from the present-day field direction (PF) and a second great circle path which passes near the expected pretilt directions (stars). AF-demagnetized sample shows a much more restricted great circle path.

this early magnetization is, in turn, obscured by a large VRM which postdates tilting of the Seamount Series.

AF demagnetization of the companion specimen (Figure 14b) also shows three components of magnetization; however, the intermediate component has a steeper inclination than in the thermally demagnetized specimen and the final component $\left(015^{\circ},-09^{\circ}\right)$ is better defined. The individual directions trace a great circle path similar to that defined by the higher temperature directions from the companion sample (Figure 14c). Since these two specimens are from the same core, the very large differences between the vector endpoint diagrams are probably a result of the variable stability of the components to $\mathrm{AF}$ and thermal demagnetization. Thus, the type of demagnetization behavior shown in Figure 6c can be produced by overlapping components of opposite polarity.

Demagnetization data from a feeder dike on the northwest flank of the Barranco de las Angustias illustrate the origin of these westerly, shallow directions (Figure 15). Thermal demagnetization of sample LP860al (Figure 15a) reveals three components: an initial westward and down component, an intermediate direction suggestive of reversed polarity, and a characteristic magnetization which approaches the expected pretilt normal direction. The directions at temperature steps $>250^{\circ} \mathrm{C}$ lie along a great circle path which passes near the expected pretilt directions (Figure 15c). The progression towards the pretilt normal direction indicates removal of a reversed pretilt magnetization. Although the characteristic magnetization is well defined, contamination by this reversed component apparently precludes isolation of the original direction. The original magnetization of the sample shown in Figure $15 \mathrm{~b}$ is almost completely obscured by secondary magnetization components. Removal of a posttilt normal component (similar to the GAD normal direction) is indicated by the great circle path defined by the low-temperature demagnetization steps (Figure 15c). At temperatures above $400^{\circ} \mathrm{C}$ the directions are compatible with a great circle path similar to that defined by sample LP860a1. The final direction $\left(328^{\circ}, 18^{\circ}\right)$ is the resultant of overlapping reversed and normal pretilt magnetizations which cannot be effectively separated. These results suggest that the westerly declinations of the normal polarity feeder dikes represent an original pretilt magnetization variably contaminated by both a pretilt reversed and a posttilt normal polarity remagnetization. The reversed polarity samples are less dispersed since both the original and remagnetization directions are of reversed polarity and predate tilting of the Seamount Series.

The mineralogical changes accompanying hydrothermal alteration may provide a mechanism for producing the aberrant 
$\mathbf{A}$

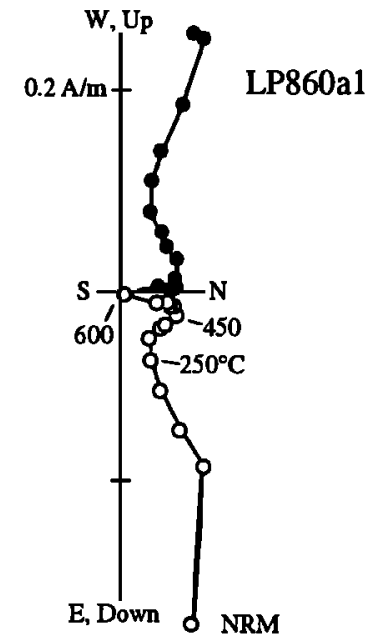

$\mathbf{B}$
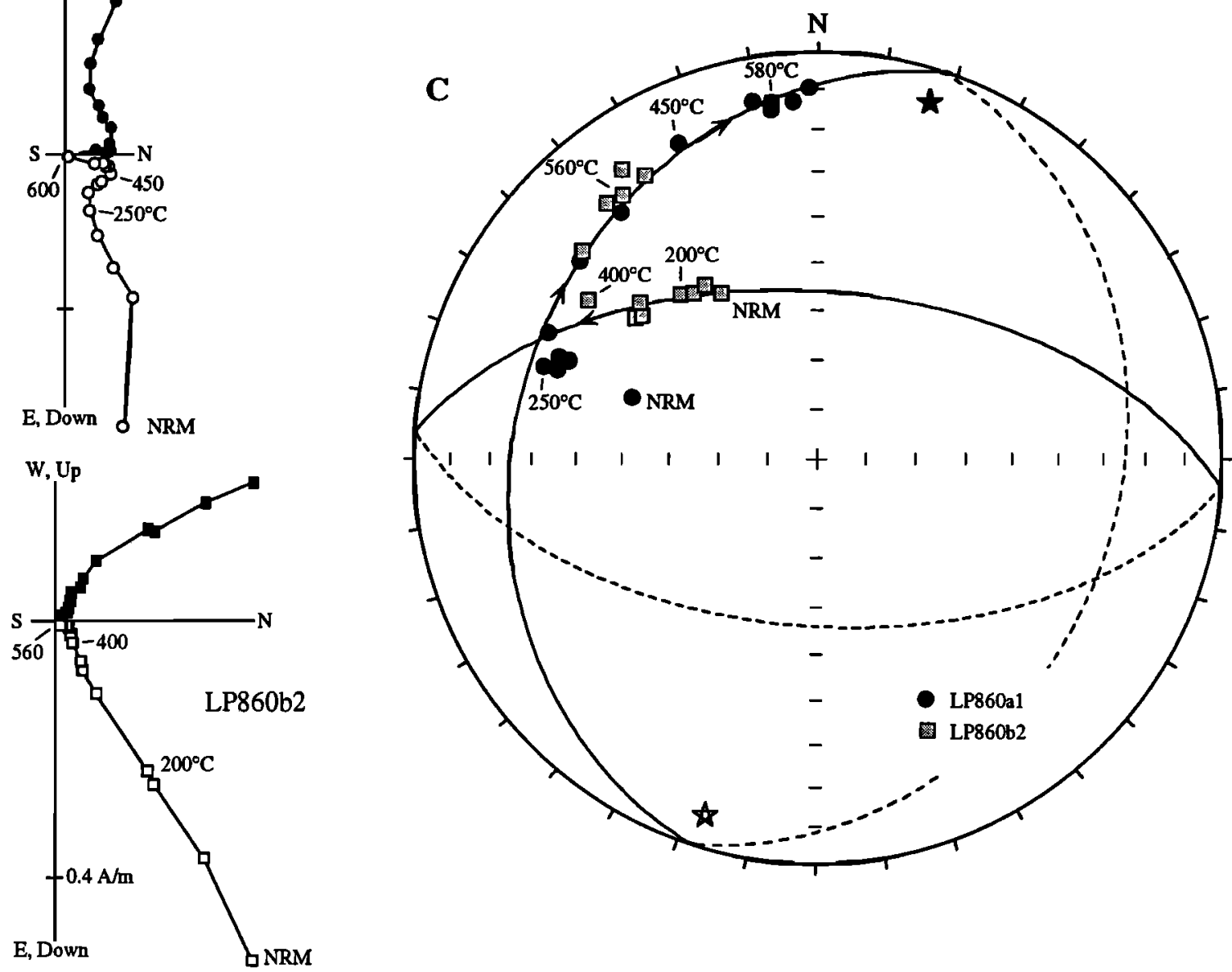

Fig. 15. Origin of shallow, northwesterly characteristic remanence directions in dike. (a)(b) Vector endpoint diagrams. Solid (open) symbols are projections of the vector onto the horizontal (vertical) plane. (c) Equal area projection of demagnetization data. Filled (open) symbols are lower (upper) hemisphere projections. Note that the individual demagnetization steps for both samples are compatible with the initial removal of a present day normal magnetization, followed by a great circle path from the reversed pretilt to the normal pretilt direction (stars).

directions observed in much of the Seamount Series. Spurious remanence directions resulting from completely overlapping blocking temperature spectra have been noted previously [e.g., Dinares-Turell and McClelland, 1991]. Such significant overlap in blocking temperatures can result from chemical overprinting [e.g., McClelland-Brown, 1982], and the presence of coexisting magnetite and hematite may account for the overlap in some samples. Tb of $<600^{\circ} \mathrm{C}$ and low stability to AF demagnetization in other samples, however, argue against the presence of hematite as a universal explanation for the discordant directions. Production of nearly pure magnetite during hydrothermal alteration may provide an alternative mechanism. Smith and Banerjee [1986] reported Ti-free secondary magnetite as a precipitant from hydrothermal fluids and also inferred the presence of submicroscopic magnetites in apparently homogeneous hydrothermally altered titanomagnetites from DSDP Hole 504B. The latter phase has recently been imaged with transmission electron microscopy, where it occurs in association with sphene, ilmenite, ulvöspinel and kassite [Shau et al., 1991]. We speculate that subdivision of primary titanomagnetite (titanomaghemite), or possibly precipitation of secondary magnetite, may result in similar populations of fine-grained magnetite which may acquire a chemical remanence parallel to the field during alteration. The inherent similarity of reversed and normally magnetized grains produced in this manner might account for the difficulty in separation by either AF or thermal demagnetization.

\section{Evolution of the Magnetization of the La Palma Seamount Series}

The construction and later alteration of the Seamount Series over several polarity intervals has resulted in a complex magnetization history. Volcanic activity at La Palma began with the eruption of lavas during the Pliocene. The dominantly normal polarity of the extrusive series, together with biostratigraphic ages of 2.9-4.0 Ma, suggests formation primarily within the Gauss normal polarity chron (2.60-3.55 Ma [Cande and Kent, 1992]). Pillow lavas acquired a TRM, presumably carried by Ti-rich titanomagnetites, as suggested by the preservation of ulvöspinel-rich titanomagnetites and nearly univectorial pretilt magnetization directions in samples from the least altered part of the section. Feeder dikes for the extrusives have pretilt directions of both normal and reversed polarity. Crosscutting relationships indicate that sill emplacement began early in the history of the seamount 
[Staudigel et al., 1986]. Sills within the extrusives have unambiguous pretilt magnetizations, confirming that at least some of the Group II intrusives were originally horizontal.

As the edifice shoaled, volcaniclastic material became more prevalent although pillow lavas also occur high in the extrusive section. Amoeboidal pillows apparently acquired a normal polarity TRM as suggested by the presence of reddened, quenched clast margins and remanence directions near the expected pretilt direction. The magnetization of most clasts in pillow fragment breccias, however, was randomized during redeposition. Sill intrusion continued during the shoaling stage: approximately $75 \%$ of sills are younger than the feeder dikes [Staudigel et al., 1986]. Although the small gabbroic intrusions sampled within the sill complex and extrusives have complex magnetizations, the shallow characteristic directions are most compatible with a pretilt remanence. Thus, the seamount must have had a significant intrusive core prior to any resolvable radial tilting.

Emplacement of intrusives also provided the source of heat for hydrothermal alteration of the Seamount Series. The mineralogical effects of this hydrothermal alteration are most apparent in the extrusives, where low-Ti magnetite was produced and hematite precipitation occurred in the most altered lavas. Much of the magnetization in extrusives may therefore best be termed a chemical remanence. Anomalous remanence directions in extrusives, as well as other lithologies, may also be attributed to hydrothermal alteration. Analysis of demagnetization data (Figures 14 and 15) indicates that these anomalous directions are most compatible with an unresolved mixture of pretilt magnetizations. The distribution of site mean directions from extrusives (Figure 11) also illustrates that the dominant alteration (remagnetization) event occurred during a reversed polarity interval. Extrusives with an original pretilt reversed magnetization have less dispersed directions, whereas the normal polarity sites are biassed toward northwesterly, shallow directions. The dominant reversed polarity of sills and gabbros provides additional support for this reversed remagnetization event. Although the precise age relationships of the intrusions are unknown, they may record either the short subchrons within the Gauss or may have intruded during the Matuyama reversed chron (but prior to the oldest Coberta lavas at $1.61 \mathrm{Ma}$ ).

Radial tilting of the Seamount Series apparently postdates hydrothermal alteration of the extrusives and is presumably the result of inflation through intrusive activity [Staudigel et al., 1986]. The emplacement of gabbros with posttilt magnetization directions probably contributed to the tilting of the Seamount Series. In addition, sills have magnetization directions similar to both the pretilt and posttilt directions, with posttilt directions most prevalent in sills nearest the center of intrusive activity (Figure 10) as might be expected if the sills were in part responsible for the tilting. The magnetization of keratophyre screens within the sill complex, however, suggests that reheating and alteration may account for some of the posttilt directions. The keratophyres represent metamorphosed trachytic extrusives from the early stages of seamount formation [Staudigel and Schmincke, 1984] and thus the original magnetization should predate tilting. A keratophyre screen from the intermediate sill site (Figure 10e) apparently maintains the original pretilt direction, whereas a keratophyre from the innermost sill site (Figure 10f) has been reheated after tilting. "Sills" nearer the caldera center may, in part, have been injected along dipping planes of weakness and may have contributed to the tilting as well as to the remagnetization of earlier sills.

Emplacement of Group III dikes and probably some gabbro intrusions occurred significantly after the formation, alteration and tilting of the Seamount Series. Field relationships, radiometric ages and posttilt magnetization directions are all compatible with the interpretation of the Group III dikes as a radial dike swarm feeding the overlying Coberta lavas. The posttilt normal polarity directions and proximity to present day hydrothermal activity in the caldera suggest that two of the gabbros sampled represent Brunhes intrusions. Finally, the majority of samples from the Seamount Series have acquired a low-stability magnetization component, similar to the present field direction at La Palma, and presumably of viscous origin.

\section{ImPLICATIONS For SEAmount Paleopoles}

The results presented in the previous sections cast doubt on the fidelity of many seamount lithologies in preserving a record of the geomagnetic field at the time of intrusion or deposition. In particular, the NRM rarely provides a good estimate of the characteristic magnetization direction, often being biassed toward the present field by a VRM. The magnetization directions of extrusives and dikes and sills emplaced early in the history of the seamount are generally consistent with a magnetization acquired prior to tilting (Table 2); however, the distribution of the characteristic magnetization suggests the presence of an incompletely removed secondary component. Thus, even directions determined from stepwise demagnetization may not represent the original magnetization. We suggest this inability to recover the original magnetization direction stems from a complex history of alteration which occurred in a different polarity state than prevalent during the original magnetization. Since the exposures in La Palma are unique in their completeness, we focus on processes affecting the magnetization which are likely to apply to other seamounts.

\section{Role of Multiple Polarities}

The presence of large volumes of material with different polarities constitutes one of the more difficult problems in seamount anomaly modeling. Lumb et al. [1973] have shown that layers of alternate polarity can lead to erroneous paleopole positions, particularly if the two polarity states are not antipodal. Multiple polarities might be detected by the spatial correlation of residuals in least squares models [e.g., Parker, 1988], and the seminorm minimization technique of Parker et al. [1987] should also detect large blocks of opposite polarity. The more recent ideal body modeling, however, suggests that even complex anomalies may be compatible with a uniform direction, provided variations in intensity are not constrained [Parker, 1991].

The duration of volcanism on ocean islands and seamounts implies that Cenozoic seamounts constructed entirely within a single polarity interval will be rare. Radiometric ages suggest a duration of 0.5 to $1.0 \mathrm{~m}$ y. for shield-building volcanism on oceanic islands [e.g., Jackson et al., 1972; McDougall and Schmincke, 1976]. The total duration of volcanism on Hawaiian Islands may span 5 m.y. [e.g., Clague and Dalrymple, 1987] and a similar duration has been documented for a Pacific seamount [Pringle et al., 1991]. Such extended volcanism, together with the high reversal frequency in the 
Cenozoic [Lowrie and Kent, 1983], suggests that multiple polarity is likely to be a common feature in moderate to large seamounts.

Results from the La Palma Seamount Series provide support for the presence of multiple polarities in many seamounts. Extrusives of the Seamount Series are dominantly of normal polarity with several reversed sites in the lower part of the section. Together with the biostratigraphically determined age of 2.9-4.0 Ma for the extrusive series [Staudigel, 1981], these results suggest that most of the extrusives erupted during the Gauss normal polarity chron. Although the precise age relationships of the intrusions are unknown, the presence of reversed sills and gabbros requires that the Seamount Series span a minimum of two reversed and one normal interval, and it may encompass much of the Pliocene. In addition to the complexity introduced by simple superposition of reversed and normal polarity material, seamount construction spanning more than one polarity interval is apparently a prerequisite for the generation of anomalous directions from hydrothermal alteration.

\section{Importance of Reheating and Hydrothermal Alteration}

The emplacement of intrusives within a seamount may be associated with either local remagnetization by conductive heating or hydrothermal alteration. Conductive heating from dike emplacement is an inefficient mechanism for remagnetizing country rock. Samples taken near dike contacts often exhibit low-stability components of magnetization with unblocking temperatures higher than expected for a lowtemperature VRM [e.g., Pullaiah et al., 1975]. The extent of the reheating indicated by these partial thermal remanence components is limited to length scales approximately equal to the width of the dike. Buchan and Schwarz [1987] reported a similar result in country rock adjacent to a $38 \mathrm{~m}$ dike in the Northwest Territories. Complete directional reorientation is confined to a smaller fraction of the dike width [e.g., Ade-Hall et al., 1972]. The average dike width $(<1 \mathrm{~m})$ in the Seamount Series suggests that the volume of country rock remagnetized by this mechanism is probably insignificant except where the dike/sill density is high. The similarity of magnetization directions in adjacent sills and the posttilt magnetization of a keratophyre screen from the innermost sill sampling locality (Figure 10f) suggest that the basal part of the sill swarm has experienced this type of reheating.

In contrast, hydrothermal alteration associated with intrusive activity can be a very effective mechanism for remagnetization [e.g., Rice et al., 1980]. If seamount construction occurs within a single polarity interval the directional changes associated with such intrusive activity would be insignificant, although the mineralogy and bulk magnetic properties would still be affected. The results from La Palma, however, indicate that intrusive activity spanning different polarity intervals may produce magnetization directions which are dramatically different from any expected geomagnetic direction (Figures 6 and 11). The similarity of the La Palma hydrothermal system to that on Reunion [Demange et al., 1989] suggests that such alteration is probably a common feature in seamounts and islands with a significant proportion of intrusives. Although hydrothermal alteration is generally confined to the early history of the seamount, Rice et al. [1980] have documented a similar remagnetization process in the Bermuda Seamount where the intrusive activity postdates seamount construction by more than $50 \mathrm{my}$.

\section{Importance of Viscous and Induced Magnetization}

In the context of determining paleopoles from seamount magnetic anomalies, probably the most general bias arises from viscous and induced magnetization (IM) contributions. The percentage of the low-stability component of magnetization in various lithologies (Figure 7) can be used to estimate the bias from VRM. The low-stability component was acquired after tilting (Figure 8). The similarity to the present field direction at La Palma, as well as evidence for alteration of the Seamount Series prior to tilting discussed above, suggests that the most plausible explanation for this component is a VRM. The general correlation between the laboratory VRM and the percentage of the low-stability component also supports this interpretation. The percentage of the low-stability magnetization does not coincide perfectly with the magnitude of VRM, since some of the secondary magnetizations are probably of thermal origin and in other cases VRM components may not be obvious from the demagnetization data. On balance, however, the parameter probably gives a reasonable estimate of the contribution of VRM.

The magnetic properties of various lithologies (Table 2) allow an estimate of the combined contribution of VRM and IM to seamount anomalies. In order to estimate this contribution, we use a model lithological distribution for a large Hawaiian-type seamount and a second model based on Jasper, an intermediate-size $\left(570 \mathrm{~km}^{3}\right)$ seamount in the eastern Pacific. On the basis of seismic and gravity data [Hill and Zucca, 1987] the model Hawaiian seamount includes $14 \%$ gabbros, $29 \%$ dikes/sills and roughly equal proportions of pillow lavas (22\%) and volcaniclastics (24\%), and $11 \%$ subaerial flows [Gee et al,, 1989]. In applying the data from Table 2 to this lithological model we have made the conservative assumptions that subaerial flows have negligible VRM and that the pillow lavas have intensities similar to the least altered samples and a VRM equal to that determined for all pillows. The resulting induced (17\% [Gee et al., 1989]) and viscous (10\%) magnetizations suggest that approximately one quarter of the total magnetization of large seamounts might have a present field direction.

Geophysical studies of Jasper Seamount [Hildebrand et al, 1989; Hammer et al., 1991] suggest that smaller seamounts have porportionately more extrusive material. We have constructed a model lithological distribution based on the observed seismic velocities in a vertical section through Jasper [Hildebrand et al., 1989] and the flexural depression of the crust to a level of $\sim 2$ below the seafloor (P. T. C. Hammer et al., Jasper Seamount structure: Seafloor seismic refraction tomography, submitted to Journal of Geophysical Research, 1993). The bulk of the seamount has seismic velocities $<4.5 \mathrm{~km} / \mathrm{s}$ which we infer to consist primarily of pillows $(65 \%)$, volcaniclastic material $(30 \%)$ with a small amount of feeder dikes (5\%). The presence of higher velocities ( $>4.5 \mathrm{~km} / \mathrm{s}$ ) beneath the flank of the seamount is thought to reflect the presence of a dike complex with $\sim 40 \%$ dikes [Hildebrand et al., 1989; P. T. C. Hammer et al., submitted mansuscript, 1993]. We have used the velocity contours as an estimate of the percentage of dikes, increasing from $40 \%$ at $4.5 \mathrm{~km} / \mathrm{s}$ to $70 \%$ at $6.5 \mathrm{~km} / \mathrm{s}$. The resulting model is compatible with the geophysical constraints and comprises $53 \%$ pillows and $18 \%$ volcaniclastic material, with less than one third intrusives. The data in Table 2 suggest a similar contribution of viscous (16\%) and induced (11\%) magnetization as inferred from the Hawaiian type model. 
Although the contribution of VRM and IM deduced from this study of the magnetic properties of seamount rocks is gratifyingly similar to the $25 \%$ inferred from modeling of seamount magnetic anomalies [Hildebrand and Staudigel, 1986; Bryan and Gordon, 1991], the estimates given above are subject to several uncertainties. Our estimate of VRM and IM does not account for the reduced contribution due to the greater depth to the intrusive sources, although the increased temperature at depth may partially offset this effect. In addition, significantly higher Koenigsberger ratios (ratio of remanent to induced magnetization, $Q$ ) have also been reported from dredged seamount samples [e.g., Gee et al., 1988], indicating a smaller IM contribution from the outermost part of seamounts. Seamount samples from drilling, however, yield intensities and $Q$ ratios similar to those from La Palma samples [e.g., Kono, 1980; Marshall, 1978], suggesting that the very high $Q$ ratios from dredged material probably are not representative of a large volume of the seamount edifice. The $\mathbf{I M}$ implied by the $Q$ ratio provides a minimum estimate of the total magnetization parallel to the ambient field, as the remanent contribution may also include a viscous component. The overall contribution of VRM and IM may be slightly lower than $25 \%$, but the percentage of the low-stability component in extrusives (15\%-22\%) suggests a minimum contribution of $15 \%$ even in seamounts dominantly composed of pillows and volcaniclastic material.

A combined viscous and induced contribution of $15 \%$ to $25 \%$ represents a significant potential error in the determination of paleolatitudes (Figure 16). The bias in paleolatitude in this figure is based on the simplest case of coplanar vectors in which a percentage of the original magnetization is reoriented parallel to the ambient field. In addition to the far-sided or near-sided pole positions generated by present field overprints [e.g. Sager, 1987], several observations may be made from this simplified model. First, the magnitude of the paleolatitude error is dependent on the polarity of the seamount. This asymmetry arises from the reduced magnetization in reversed polarity seamounts due to a normal polarity overprint, resulting in a proportionately greater angular deviation from the same magnitude overprint. Paleopoles from reversed seamounts are far-sided by an amount $\sim 50 \%$ greater than the corresponding near-sided bias of a normally magnetized seamount. Second, the paleolatitude error is also dependent on the original paleolatitude of the seamount. For example, a reversed seamount formed at $20^{\circ} \mathrm{S}$ and now at $5^{\circ} \mathrm{N}$ has a paleopole which is far-sided by $14^{\circ}$ if $\mathrm{IM}$ and VRM account for $25 \%$ of the seamount magnetic anomaly. A reversed seamount constructed at $20^{\circ} \mathrm{N}$ and subject to the same latitudinal transport $\left(25^{\circ}\right)$ would yield a pole position only $7.5^{\circ}$ far-sided. Therefore, the bias introduced by viscous and induced magnetization is significant for older Pacific seamounts. Fixed hotspot models suggest $\sim 40^{\circ}$ of northward motion for the Pacific plate since the late Cretaceous [e.g. Engebretson et al., 1985]. We note that the majority of Cretaceous paleopoles used to construct the Pacific apparent polar wander path are from seamounts presently located at low latitudes. Many of these seamounts were presumably constructed at low southern latitudes and therefore might have paleopoles in error by up to $10^{\circ}$ to $16^{\circ}$ for normal and reversed polarity seamounts, respectively.

\section{Conclusions}

The La Palma Seamount Series constitutes a single sample suite representing the interior of a seamount, but in the absence of significant drilling penetration into seamounts these results provide the best opportunity to evaluate the assumptions inherent in determining paleopoles from seamount magnetic anomalies. The fundamental assumption of such modeling is that the anomaly is dominated by a remanent magnetization which preserves an accurate record of the geomagnetic field

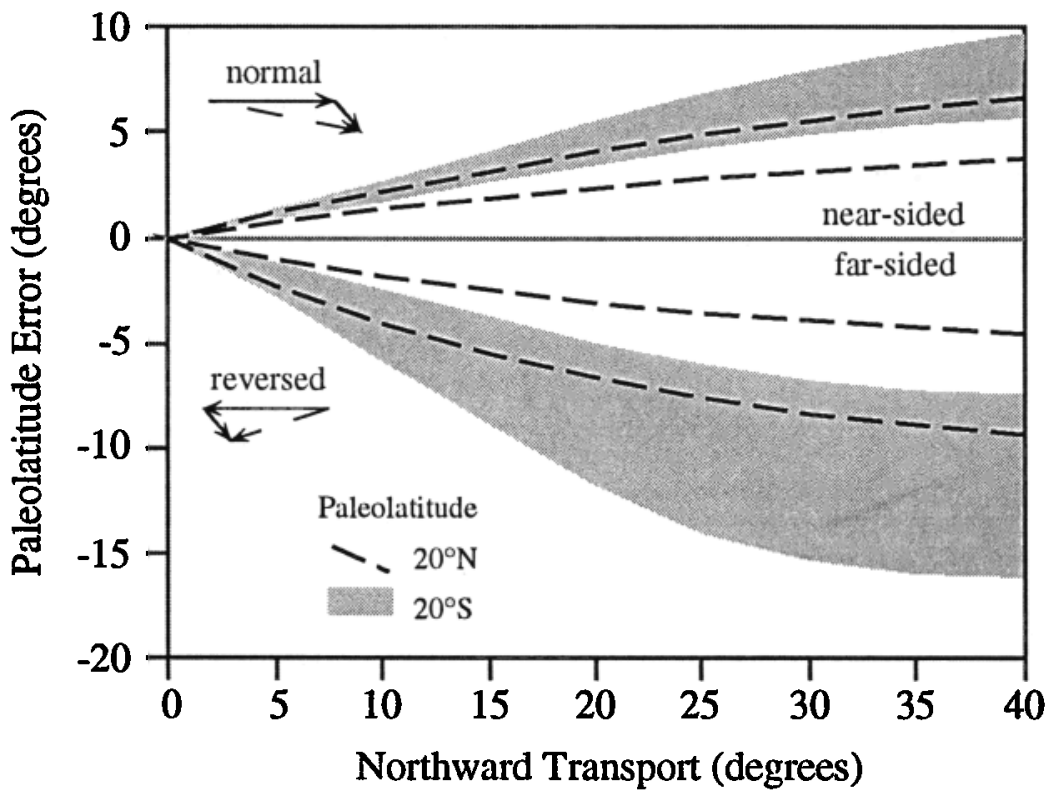

Fig. 16. Potential bias in seamount paleopoles resulting from viscous and induced magnetization. Paleolatitude error applicable to Pacific plate is shown for normal and reversed polarity seamounts constructed at $20^{\circ} \mathrm{N}$ (areas between dashed lines) and $20^{\circ} \mathrm{S}$ (shaded areas) as a function of northward transport. The range of the potential paleolatitude error in each of the four cases corresponds to a combined viscous and induced contribution ranging from $15 \%$ to $25 \%$. Note that bias is dependent not only on latitudinal displacement but is also a function of seamount polarity and paleolatitude. Paleolatitude ernor calculated from simple coplanar vector model with percentage of original remanence reoriented into ambient field direction. 
during seamount construction. Despite the high $\mathbf{Q}$ ratios often reported from dredged/drilled seamount samples [e.g., Kono, 1980; Gee et al., 1988], a significant $\mathbf{I M}$ is expected from lithologies within the seamount interior [Gee et al, 1989]. The NRM directions of La Palma samples also give a poor representation of the characteristic magnetization direction. The distribution of NRM directions is strongly biassed toward the present field direction, rather than reflecting the original pretilt direction as required by anomaly modeling. The mean direction $\left(352.3^{\circ}, 46.8^{\circ}\right)$ of the low-stability component of magnetization, together with laboratory viscous acquisition experiments, suggests this component can reasonably be ascribed to a recent VRM. The magnitude of the lowstability component and the average $Q$ ratios of La Palma samples imply a combined $\mathbf{M}$ and VRM contribution of $15 \%-25 \%$, with the lesser value probably applicable for smaller seamounts dominated by extrusive material. The bias introduced by viscous and induced magnetization is dependent not only on the amount of latitudinal translation, but is also a function of the polarity and paleolatitude of seamount formation.

The induced and viscous contribution to seamount magnetization derived from our study suggests several approaches for evaluating the reliability of individual seamount paleopoles as well as for possibly improving the Pacific apparent polar wander path. The relative contribution of IM and VRM is dependent on lithology, with greater contributions associated with intrusive material. As suggested previously [Gee et $a l ., 1989$ ], the average density might be used to identify seamounts with a high proportion of intrusives and therefore a potentially larger bias due to viscous and induced magnetization. In addition, comparison of solutions from the various modeling techniques provides an indication of the error for an individual paleopole determination. For example, the ideal body, seminorm and least-squares solutions for Darwin Guyot, a large seamount formed in the early Cretaceous, differ by more than $20^{\circ}$ [Parker, 1991]. Some estimate of the potential paleopole error may also be derived by modeling the seamount anomaly after removal of an estimated VRM and $\mathrm{IM}$ contribution parallel to the ambient field. The overall contribution of $15 \%-25 \%$ may be appropriate for many seamounts, although additional geophysical constraints on the internal structure of the seamount are obviously desirable to construct a geologically reasonable model. Finally, we suggest that paleopoles modified in this way may provide a more realistic estimate of plate motion. The asymmetry of the paleolatitude bias should be considered when combining such corrected paleopoles from seamounts of different polarity.

Our data from La Palma also indicate that preservation of the original magnetization direction may be affected by hydrothermal alteration, which results in the production of low-Ti magnetite and an increasing contribution of hematite to the remanence. In addition to significant changes in the bulk magnetic properties, magnetization directions which deviate significantly from any reasonable geomagnetic direction at La Palma can be attributed to hydrothermal alteration in a different polarity than prevalent during the original magnetization. Seamount construction over multiple polarity intervals, when coupled with hydrothermal alteration, may therefore result in additional complications besides the simple superposition of rocks of different polarity. These results suggest that small seamounts, with little intrusive material and possibly less hydrothermal activity, and seamounts constructed within a single polarity interval may provide the best opportunity for determining paleopoles.

The effects of hydrothermal alteration noted in La Palma samples suggest that caution should be excercised in interpreting results from similarly altered lavas. Hydrothermal alteration may offer an alternative explanation for similar anomalous remanence directions often encountered in drilled samples from the ocean crust and attributed to tectonic tilting. The potential severity of this problem is limited, however, by the lower temperatures prevalent in the extrusive portion of the crust. For example, the geothermal gradient at DSDP Hole $504 \mathrm{~B}$ results in temperatures $>100^{\circ} \mathrm{C}$ only at the base of the extrusive layer and deeper [Becker et al., 1989]. The bulk of the extrusives would presumably not be subject to the alteration temperatures sufficient to cause the mineralogical changes noted in extrusives from La Palma except in cases where sediment cover is especially thick.

Acknowledgments. We thank J. L. G. Afonso, C. Alba, A. P. Martinez, U. Tams and the Weinrich family for logistical support and L. Stokking and E. Barg for assisting in the field work. We thank M. Collins and J. Collins for help in measuring samples. We are grateful to $\mathbf{R}$. Enkin for providing a great circle analysis program. We are indebted to $P$. Schiffman for his contributions to unraveling the alteration history of the La Palma samples as well as providing use of an electron microprobe. Special thanks are extended to D. V. Kent and E. L. Winterer for many helpful discussions. M. Tivey, J. Hall, and C. Raymond provided thorough reviews which greatly improved the text. The Keck Foundation kindly provided support for the Scripps Paleomagnetic Laboratory. This project has been supported by the National Geographic Society and NSF grant OCE90-00182. J. Gee was partially supported by an NSF graduate fellowship.

\section{REFERENCES}

Abdel-Monem, A., N. D. Watkins, and P. W. Gast, Potassium-argon ages, volcanic stratigraphy, and geomagnetic polarity history of the Canary Islands: Tenerife, La Palma, and Hierro, Am. J. Sci., 272, 805-825, 1972.

Ade-Hall, J. M., P. Dagley, R. L. Wilson, A. Evans, A. Riding, P. J. Smith, R. Skelhome, and T. Sloan, A palaeomagnetic study of the Mull regional dyke swarm, Geophys. J. R. Astron. Soc., 27, 517-545, 1972.

Ade-Hall, J. M., H. C. Palmer, and T. P. Hubbard, The magnetic and opaque petrological response of basalts to regional hydrothermal alteration, Geophys. J. R. Astron. Soc., 24, 137-174, 1971.

Afonso, A., Geological sketch and historic volcanoes in La Palma, Canary islands, Estud. Geol., Teneguia Vol., 7-13, 1974.

Barone, A. M., and W. B. F. Bryan, Single plume model for asynchronous formation of the Lamont Seamounts and adjacent East Pacific Rise terrains, J. Geophys. Res., 95, 10,801-10,827, 1990.

Becker, K., et al., Drilling deep into young oceanic crust, Hole 504B, Costa Rica Rift, Rev. Geophys., 27, 79-102, 1989.

Bird, D. K., P. Schiffman, W. Elders, and A. E. Williams, Calcsilicate mineralization in active geothermal systems, Econ. Geol. 79, 671-695, 1984.

Bryan, P., and R. G. Gordon, Determining the average contribution of viscous overprints to the characteristic magnetization of $\mathrm{Pa}$ cific searnounts (abstract), Eos Trans. AGU, 72(44) Fall Meeting suppl., 125, 1991.

Buchan, K. L., and E. J. Schwarz, Determination of the maximum temperature profile across dyke contacts using remanent magnetization and its applications, in Mafic Dyke Swams, edited by H. C. Halls and W. F. Fahrig, Geol. Assoc. Can. Spec. Pap., 34, 221-227, 1987.

Carmichael, I. S. E., The iron-titanium oxides of salic volcanic rocks and their associated ferromagnesian silicates, Contrib. Mineral. Petrol., 14, 36-64, 1967.

Carmichael, I. S. E., and J. Nicholls, Iron-titanium oxides and oxygen fugacities in volcanic rocks, J. Geophys. Res., 72, 4665-4687, 1967. 
Clague, D. A., and G. B. Dalrymple, The Hawaiian-Emperor volcanic chain, part I, Geologic evolution, in Volcanism inHawaii, U.S. Geol. Surv. Prof. Pap., 1350, 5-54, 1987.

Cox, A., Latitude dependence of the angular dispersion of the geomagnetic field, Geophys. J. R. Astron. Soc., 20, 253-269, 1970.

Demange, J., P. Chovelon, and P. Puvilland, Geothermal model of the Salazie Cirque (Reunion Island): Volcanic and structural implications, J. Volcanol. Geothem. Res., 36, 153-176, 1989.

Dinares-Turell, J., and E. McClelland, A cautionary tale for palaeomagnetists: A spurious apparent single component remanence due to overlap of blocking-temperature spectra of two components, Geophys. Res. Lett., 18, 1297-1300, 1991.

Dunlop, D. J., Theory of the magnetic viscosity of lunar and terrestrial rocks, Rev. Geophys., I1, 855-901, 1973.

Dunlop, D. J., Viscous magnetization of $0.04-100 \mu \mathrm{m}$ magnetites, Geophys. J. R. Astron. Soc., 74, 667-687, 1983.

Engebretson, D. C., A. Cox, and R. G. Gordon, Relative motions between oceanic and continental plates in the Pacific Basin, Spec. Pap. Geol. Soc. Am., 206, 59 pp., 1985.

Fisher, R. V., and H.-U. Schmincke, Pyroclastic Rocks, 472 pp., Springer-Verlag, New York, 1984.

Fornari, D. J., A. Malahoff, and B. C. Heezen, Volcanic structure of the crest of Puna Ridge, Hawaii: Geophysical implications of submarine volcanic terrain, Geol. Soc. Am. Bull., 89, 605-616, 1978.

Francheteau, J., C. G. A. Harrison, J. G. Sclater, and M. L. Richards, Magnetization of Pacific seamounts: A preliminary polar curve for the northeastem Pacific, J. Geophys. Res., 75, 2035-2061, 1970.

Fujimoto, K., and E. Kikawa, Alteration of titanomagnetites and its related magnetic properties in the Noya geothermal area, Central Kyushu, Japan, J. Geomagn. Geoelectr, 41, 39-64, 1989.

Gee, J., L. Tauxe, J. A. Hildebrand, H. Staudigel, and P. Lonsdale, Nonuniform magnetization of Jasper Seamount, J. Geophys. Res., 93, 12,159-12,175, 1988.

Gee, J., H. Staudigel, and L. Tauxe, Contribution of induced magnetization to magnetization of seamounts, Nature, 342, 170-173, 1989.

Gordon, R. G., Test for bias in paleomagnetically detennined paleolatitudes from Pacific plate Deep Sea Drilling Project sediments, J. Geophys, Res., 95, 8397-8404, 1990.

Gordon, R. G., and A. Cox, Calculating palaeomagnetic poles for oceanic plates, Geophys. J. R. Astron. Soc., 63, 619-640, 1980.

Haggerty, S. E., Oxidation of opaque mineral oxides in basalts, in Oxide Minerals, Mineral. Soc. Am. Short Course Notes, edited by D. Rumble, III, pp. 101-140, Mineralogical Society of America, Washington, D.C., 1976

Hall, J. M., and B. E. Fisher, The characteristics and significance of secondary magnetite in a profile through the dike component of the Troodos, Cyprus, ophiolite, Can. J. Earth Sci., 24, 2141-2159, 1987.

Hall, J. M., C. Walls, M. Williamson, and B.-X. Wang, Depth trends in magnetic properties in an area of prolonged cold seawater drawdown in uppermost Troodos-type oceanic crust, Can. J. Earth Sci., 24. 941-952, 1987.

Hammer, P. T. C., J. A. Hildebrand, and R. L. Parker, Gravity inversion using seminorm minimization: Density modeling of Jasper Seamount, Geophysics, 56, 68-79, 1991.

Harrison, C. G. A., A seamount with a nonmagnetic top, Geophysics, 36, 349-357, 1971 .

Harrison, C. G. A., and M. M. Ball, Geophysical observations on an exposed seamount in the Afar Depression, Bull. Volcanol., 38, $26-43,1975$.

Hayes, D. E., and P. D. Rabinowitz, Mesozoic magnetic lineations and the magnetic quiet zone off North West Africa, Earth Planet. Sci. Lett., 28, 105-115, 1975.

Hemandez-Pacheco, A., and S. Fernandez-Santin, The submarine formations of the Caldera de Taburiente in La Palma (Canary Islands) and their metasomatic processes, IAVCEI Symposium, Santiago de Chile, Bull. Volcanol. Spec. Vol., 1975.

Hildebrand, J. A., and H. Staudigel, Seamount magnetic polarity and Cretaceous volcanism of the Pacific Basin, Geology, 14, 456-458, 1986.

Hildebrand, J. A., L. M. Dorman, P. T. C. Hammer, A. E. Schreiner, and B. D. Comuelle, Seismic tomography of Jasper Seamount, Geophys. Res. Lett., 16, 1355-1358, 1989.
Hill, D. P., and J. J. Zucca, Geophysical constraints on the structure of Kilauea and Mauna Loa volcanoes and some implications for seismomagmatic processes, U. S. Geol. Surv. Prof. Pap., 1350, 903-917, 1987.

Jackson, E. D., E. A. Silver, and G. B. Dalrymple, Hawaiian-Emperor Chain and its relation to Cenozoic circum-Pacific tectonics, Geol. Soc. Am. Bull., 83, 601-618, 1972.

Johnson, H. P., and R. T. Merrill, Low-temperature oxidation of a titanomagnetite and the implications for paleomagnetism, J. Geophys. Res., 78, 4938-4949, 1973.

Kent, D. V., and W. Lowrie, VRM studies in leg 37 igneous rocks, Initial Rep. Deep Sea Drill. Proj., 37, 525-529, 1977.

Kirschvink, J. L., The least-squares line and plane and the analysis of paleomagnetic data, Geophys. J. R. Astron. Soc., 62, 699-718, 1980.

Kono, M., Magnetic properties of DSDP leg 55 basalts, Initial Rep. Deep Sea Drill. Proj., 55, 723-736, 1980.

Liou, J. G., Analcime equilibria, Lithos, 4, 389-402, 1971.

Lonsdale, P., and R. Batiza, Hyaloclastite and lava flows on young seamounts examined with a submersible, Geol. Soc. Am Bull., 91, 545-554, 1980.

Lowrie, W., Identification of ferromagnetic minerals in a rock by coercivity and unblocking temperature properties, Geophys. Res. Lett., 17, 159-162, 1990.

Lowrie, W., and D. V. Kent, Magnetic reversal frequency since the Late Cretaceous, Earth Planet. Sci. Lett., 62, 305-313, 1983.

Lumb, J. T., M. P. Hochstein, and D. J. Woodward, Interpretation of magnetic measurements in the Cook Islands, south-west Pacific Ocean, in The Western Pacific: Island Arcs, Marginal Seas and Geochemistry, edited by P. J. Coleman, Pp. 79-101, Crane, Russak, New York, 1973.

Marshall, M., The magnetic properties of some DSDP basalts from the North Pacific and inferences for Pacific plate tectonics, J. Geophys. Res., 83, 289-308, 1978.

McClelland-Brown, E., Discrimination of TRM and CRM by blocking-temperature spectrum analysis, Phys. Earth Planet. Inter., $30,405-414,1982$.

McDougall, I., and H.-U. Schmincke, Geochronology of Gran Canaria, Canary Islands: Age of shield building volcanism and other magmatic phases, Bull. Volcanol., 40, 1-21, 1976.

McFadden, P. L., and M. W. McElhinny, A physical model for palaeosecular variation, Geophys. J. R. Astron. Soc., 78, 809$830,1984$.

McFadden, P. L., and M. W. McElhinny, The combined analysis of remagnetization circles and direct observations in palaeomagnetism, Earth Planet. Sci. Lett., 87, 161-172, 1988.

McNutt, M., Nonuniform magnetization of seamounts: A least squares approach, J. Geophys. Res., 91, 3686-3700, 1986.

Middlemost, E. A. K., Evolution of La Palma, Canary Archipelago, Contrib. Mineral. Petrol., 28, 272-279, 1972.

O'Reilly, W., Rock and Mineral Magnetism, 220 pp., Chapman and Hall, New York, 1984.

Palmasson, G., S. Amorson, I. B. Freidleifsson, H. Kristmannsdottir K. Saemundsson, V. Stefansson, B. Steingrisson, and J. Tomasson. The Iceland crust: evidence from drillhole data on structure and processes, in Deep Drilling Results in the Atlantic Ocean: Ocean Crust, Maurice Ewing Ser., vol. 2, edited by M. Talwani, C. G. A. Harrison, and D. E. Hayes, pp. 43-65, AGU, Washington, D.C., 1979.

Parker, R. L., A statistical theory of seamount magnetism, J. Geophys. Res., 93, 3105-3115, 1988.

Parker, R. L., A theory of ideal bodies for seamount magnetism, $J$. Geophys. Res., 96, 16,101-16,112, 1991.

Parker, R. L., L. Shure, and J. A. Hildebrand, The application of inverse theory to seamount magnetism, Rev. Geophys., 25, 1740, 1987.

Pick, T. S., and J. S. Gee, Magnetic petrology of hydrothermally altered pillow basalts from the La Palma Seamount Series (abstract), Eos Trans. AGU, 72(44) Fall Meeting suppl., 144, 1991.

Press, W. H., B. P. Flaunery, S. A. Teukolsky, and W. T. Vetterling, Numerical Recipes: The Art of Scientific Computing, 702 pp., Cambridge University Press, New York, 1986.

Pringle, M. S., H. Staudigel, and J. Gee, Jasper Seamount: Seven million years of volcanism, Geology, 19, 364-368, 1991.

Pullaiah, G., E. Irving, K. L. Buchan, and D. J. Dunlop, Magnetization changes caused by burial and uplift, Earth Planet. Sci. Lett., $28,133-143,1975$. 
Ramdohr, P., The Ore Minerals and their Intergrowths, 1207 pp., Pergamon, New York, 1969.

Rice, P. D., J. M. Hall, and N. D. Opdyke, Deep Drill 1972: A paleomagnetic study of the Bermuda Seamount, Can. J. Earth Sci., 17, 232-243, 1980.

Ryall, P. J. C., and J. M. Hall, Laboratory alteration of titanomagnetites in submarine pillow lavas, Can. J. Earth Sci., 16, 496-504, 1978.

Sager, W. W., Late Eocene and Maastrichtian paleomagnetic poles for the Pacific plate: Implications for the validity of seamount paleomagnetic data, Tectonophysics, 144, 301-314, 1987.

Schmincke, H. -U., The geology of the Canary Islands, in Biogeography and Ecology in the Canary Islands, edited by G. Kunkel, pp. 67-184, W. Junk, The Hague, 1976.

Shau, Y.-H., D. R. Peacor, and E. J. Essene, Single-domain-sized magnetite $\left(\mathrm{Uv}_{0}\right)$ after titanomagnetite in hydrothemally altered oceanic basalt (abstract), Eos Trans. AGU, 72(17) Spring Meeting suppl., 141, 1991.

Smith, G. M., and S. K. Banerjee, Magnetic structure of the upper kilometer of the marine crust at Deep Sea Drilling Project hole 504B, eastem Pacific Ocean, J. Geophys. Res., 91, 10,33710,354, 1986.

Staudigel, H., Der basale Komplex von La Palma, submarine vulkanische Prozesse, Petrologie, Geochemie und sekundäre Prozesse im herausgehobenen, submarinen Teil einer ozeanischen Insel, Ph.D. thesis, 357 Pp., Ruhr Univ., Bochum, Germany, 1981.

Staudigel, H., and H.-U. Schmincke, The Pliocene Seamount Series of La Palma/Canary Islands, J. Geophys. Res., 89, 11,195-11,215, 1984.

Staudigel, H., G. Feraud, and G. Giannerini, The history of intrusive activity on the island of La Palma (Canary Islands), J. Volcanol. Geotherm. Res., 27, 299-322, 1986.
Steiger, R. H., and E. Jäger, Subcommission on geochronology, Earth Planet. Sci. Lett., 36, 359-362, 1977.

Steinthorsson, S., and A. E. Sveinbjömsdottir, Opaque minerals in geothermal well no. 7, Krafla, northern Iceland, J. Volcanol. Geotherm. Res., 10, 245-261, 1981.

Tivey, M., and H. P. Johnson, The characterization of viscous remanent magnetization in large and small magnetite particles, $J$. Geophys. Res., 89, 543-552, 1984.

Vacquier, V., A machine method for computing the magnitude and the direction of magnetization of a uniformly magnetized body from its shape and a magnetic survey, in Proceedings of Benedum Earth Magnetism Symposium, pp. 123-137, University of Pittsburgh Press, Pittsburgh, Pa, 1962.

Zijderveld, J. D. A., A.C. demagnetization of rocks: analysis of results, in Methods in Palaeomagnetism, edited by D. W. Collinson, K. M. Creer, and S. K. Runcom, pp. 254-286, Elsevier, New York, 1967

Y. Gallet, Institut de Physique du Globe de Paris, 4 Place Jussieu, 75252 Paris Cedex 05, France.

J. Gee, Lamont-Doherty Earth Observatory, Palisades, New York, 10964.

T. Pick and L. Tauxe, Scripps Institution of Oceanography, La Jolla, CA 92093-0220.

H. Staudigel, Vrije Universiteit Amsterdam, Fac. der Aardwetenschappen, De Boelelaan 1085, 1081 HV Amsterdam, Netherlands.

(Received July 10, 1992;

revised March 11, 1993;

accepted April 9, 1993.) 